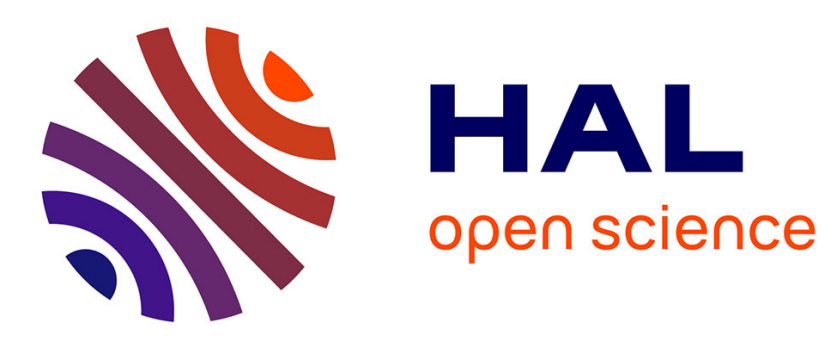

\title{
Interaction of Metal Complexes with G-Quadruplexes
}

\author{
Olivier Jarjayes, Thomas Lavergne, Fabrice Thomas
}

\section{To cite this version:}

Olivier Jarjayes, Thomas Lavergne, Fabrice Thomas. Interaction of Metal Complexes with GQuadruplexes. Encyclopedia of Inorganic and Bioinorganic Chemistry, 1, Wiley, 2011, 9781119951438. 10.1002/9781119951438.eibc2748 . hal-03001783

\section{HAL Id: hal-03001783 https://hal.science/hal-03001783}

Submitted on 16 Nov 2020

HAL is a multi-disciplinary open access archive for the deposit and dissemination of scientific research documents, whether they are published or not. The documents may come from teaching and research institutions in France or abroad, or from public or private research centers.
L'archive ouverte pluridisciplinaire HAL, est destinée au dépôt et à la diffusion de documents scientifiques de niveau recherche, publiés ou non, émanant des établissements d'enseignement et de recherche français ou étrangers, des laboratoires publics ou privés. 


\section{Interaction of metal complexes with G-quadruplexes}

Olivier Jarjayes, Thomas Lavergne and Fabrice Thomas

Univ. Grenoble Alpes, CNRS, DCM, F-38000 Grenoble, France.

1. Introduction

2. G-quadruplexes

3. Factors governing the interaction with metal complexes

4. Main families of molecular complexes

5. Supramolecular assemblies

6. Platination

7. Bioconjugates

8. Reactivity with adducts formed between $\mathrm{G} 4$ and metal complexes

9. Biological applications of inorganic $\mathrm{G} 4$ binders

10. Summary and outlook

11. References 


\section{Introduction}

Guanine rich sequences were identified in distinct locations within the genome, and proposed to be ubiquitous in the human genome. They confer to DNA the ability to fold under a specific topology known as G-quadruplex (G4) in these regions. G4 helixes consist of stacked G-quartets, themselves formed by the association of four guanines. ${ }^{1}$ The structure contains a central channel filled with alkali metal ions, which further contribute to the stabilization through electrostatic interactions with the carbonyl moieties of the guanines. They can be intramolecular, but also intermolecular with up to four strands connected together. A peculiarity of the G4 is their great polymorphism, affording structures with different orientations of the strands and loops and various depths and width of the grooves. $^{2}$

There is significant evidence suggesting that $\mathrm{G} 4$ assemble transiently in the human genome and play important regulatory roles. G4 are for example found in the promoter region of some oncogenes (cmyc, kit, KRAS). ${ }^{3}$ Their stabilization by adding a strong and specific G4 binder (that freezes the G4 structure) results in a down-regulation of these genes. ${ }^{4} \mathrm{G} 4$ are also found in the non-coding ends (telomeres) of the chromosomes and play a key role in the telomere homeostasis, together with the enzyme telomerase. This latter enzyme counter-balances the natural telomere erosion by adding short non-coding sequences. This enzyme is repressed in normal cells, but over-expressed in $85 \%$ of cancer cells, hence contributing to their immortality. The formation and stabilization of G4 results in an inhibition of telomerase activity and hence constitutes a promising approach for designing new anti-cancer drugs. ${ }^{5}$ These therapeutic opportunities have stimulated the development of G4 binders, which have grown exponentially during the past decade. Organic and inorganic binders were designed, with distinct selectivity and affinity, and sometime bringing functionalities or reactivity. The specific recognition of $\mathrm{G} 4$, which is required for cellular applications, is based on the targeting of specific features, often the upper tetrad that exposes a large aromatic surface to the solvent. Additional interaction with the loops and grooves are also exploited. While a great number of organic molecules were reported, telomestatin ${ }^{6}$ and BRACO- $19^{7}$ being staple $\mathrm{G} 4$ binders, metal complexes have emerged as powerful alternative platforms. By combining the effects of the positively charged metal, which can be involved in electrostatic interactions with electronegative regions, and aromatic rings (chelating or not) designed to interact through $\pi$-stacking, strong $\mathrm{G} 4$ binders were obtained. The typical versatility of the ligands and complexes synthesis allows for easy screening and hence convenient optimization, while offering the possibility to incorporate reactive fragments. All these aspects will be discussed in the upcoming sections in a complementary way to important reviews on the topic. ${ }^{8-12}$ In a preamble we will present the main determinants for the $\mathrm{G} 4$ folding and its roles. 


\section{G-quadruplexes}

\subsection{Structure and polymorphism}

G4 are four-stranded nucleic acid structures formed by the stacking of two or more guanine quartets (G-quartets) (Figure 1). G-quartets (also termed tetrads) are formed by the planar association of four guanines which hold together thanks to Hoogsteen-type hydrogen bounds (Figure 1). G-quartets are further stabilized by metal cations such as $\mathrm{K}^{+}$and $\mathrm{Na}^{+}$which coordinate the $\mathrm{O} 6$ of the guanines thereby preventing electronic repulsion. An intramolecular DNA G4 structure folded by a single Grich strand can adopt various topologies depending on the polarity of the individual G-tracts constituting the structure (Figure 2). ${ }^{2}$ Within a parallel G4 structure all four G-tracts have the same directionality and the connecting sequences are called propeller (or chain reversal) loops. Within an antiparallel G4 structure two runs of guanines have a 5'-3' direction and the two other runs have the opposite direction. The connecting loops within an antiparallel G4 are either lateral if they join adjacent tracts of guanines or diagonal if they join diagonally opposite tracts of guanines. Finally, within a hybrid G4 structure one tract of guanine run in opposite direction to the other three tracts and all type of loops might be formed upon folding onto such topology. Beyond those typical G4 topologies, less usual structures possessing bulges, vacant sites or long loops have also been described and higher order G4 aggregates may also form. ${ }^{13}$ Depending on the relative strand orientations, the glycosidic bond of the guanines will adopt anti or syn geometry (Figure 2). In RNA G4, the 2'-hydroxyl groups cause steric constraints which favor the anti conformation therefore promoting the formation of parallel topologies.

A

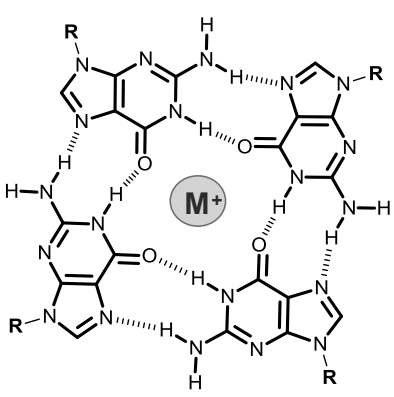

B

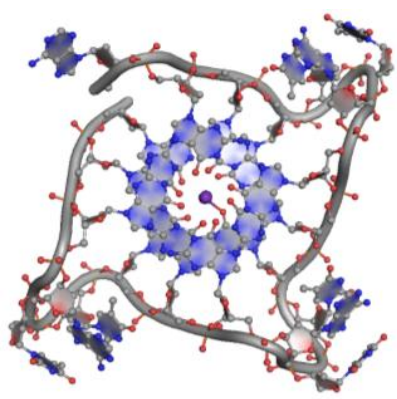

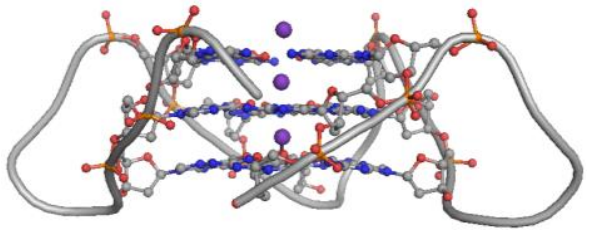

Figure 1. A/ Structure of a G-quartet. B/ Top view (left) and side view (right) of the crystal structure of a human telomeric G4s (PDB: 1KF1), loop residues are omitted in the side view for clarity.

A

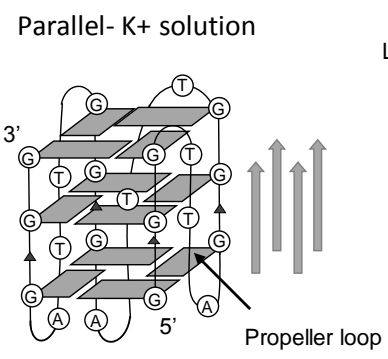

Hybrid- K+ solution

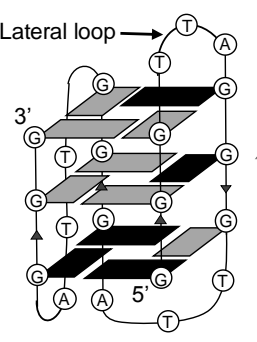

B

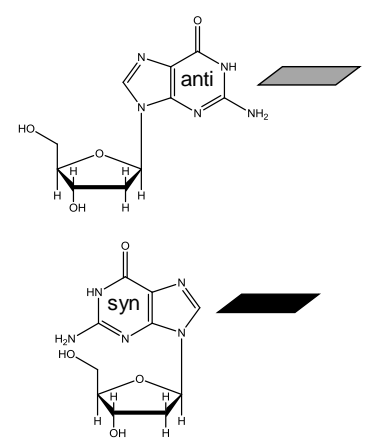


Figure 2. A/ Schematic drawing of three distinct G4 topologies observed with the telomeric sequence, black box $=($ syn) guanine, grey box $=($ anti) guanine, arrows indicate strand polarity. B/ Anti and syn glycosidic bonds.

It has been shown that, in vitro, the folding of DNA G4 into one or the other topology is dictated by several parameters such as the sequence context, the nature of the metal cation, the ionic strength and the presence of crowding agents. ${ }^{14}$ The human telomeric $\mathrm{G} 4$ sequence, which consist in TTAGGG repeats, is one of the best models for such dynamic polymorphism as many distinct conformations have been observed depending on the folding conditions (three of them are shown in Figure 2). ${ }^{15}$ Various methods might be used to elucidate such structures including circular dichroism (CD) spectroscopy which display characteristic spectral signatures depending on the type of topology. ${ }^{16}$ CD spectroscopy has also been used to demonstrate that G4 structures usually possess high stabilities with melting temperatures above $60^{\circ} \mathrm{C}$.

\subsection{Occurrence}

G4 have initially received much attention because of their occurrence at telomeres and their connection with telomerase. ${ }^{17}$ In humans, the telomeric sequence consists of (TTAGGG) $n$ repeats with a double-stranded portion of several thousand bases in length and a single stranded overhang of a few hundred bases. The formation of G4 structures at the telomere has been evidenced by the recognition of the telomere by G4-specific antibodies, such as BG4. ${ }^{18}$ Early bioinformatics studies, using the assumption that $G 4$ may arise from the sequences $G_{x} N_{y} G_{x} N_{y} G_{x} N_{y} G_{x}$ in which $x$ ranges from 3 to 5 and y between 1 and 7 bases long, showed that the human genome possesses about 370,000 putative G4 forming sequences (PQS). ${ }^{19}, 20$ More recent re-evaluation of the G4 propensity using the G4hunter algorithm suggest that the PQS number in the human genome is in fact significantly higher, ${ }^{21}$ while a high-throughput G4 sequencing allowed for the identification of ca. 700000 distinct G4 structures. ${ }^{22}$ Consistently, about $10000 \mathrm{G} 4$ structures were identified in human chromatin by using a G4 specific antibody for chromatin immunoprecipitation followed by high-throughput sequencing (G4 ChIP-seq). ${ }^{23}$ Strikingly, the G4 structures predicted by the algorithms or identified by sequencing are not randomly distributed, but are predominantly found in regulatory regions such as gene promoters (often near transcription start sites), origins of replications and 5'-UTRs of RNA. About $50 \%$ of human gene promoters contain one or more G4 forming sequence, suggesting the involvement of G4 in regulating the transcription. In RNA they are predominantly found in untranslated transcribed regions (UTRs), but not exclusively. They are also found in long non coding RNAs, which are known to play significant roles in various biological processes. Beyond the human genome, G4 have been spotted in regulatory regions of the genomes of various pathogens and especially in viruses such as HIV-1, HBV, HCV or more recently, Zika. ${ }^{24}$

\subsection{Biological functions}

The telomeric G-rich sequence plays multiple roles to maintain the telomere stability and replication in healthy cells. G4 structures inhibit the activity of telomerase, the enzyme responsible for the maintenance of the telomere length. ${ }^{25}$ To prevent G4 mediated telomere shortening, particular DNA helicases and ssDNA binding proteins are able to unwind G4. ${ }^{26}$ For example, POT1 is able to bind G4 overhangs and disrupt the $\mathrm{G} 4$ structure, hence making the telomere more accessible for telomerase 
mediated length regulation. ${ }^{27}$ On the other hand, the G4 structure is believed to have protecting effects. By recruiting POT1, G4 structures contribute to prevent the binding of the replication protein at the telomeres, whose accumulation activate DNA damage signals. ${ }^{28}$ In most cancer cells the telomerase is highly expressed, preventing telomere shortening and leading to cell replicative immortality. Telomeric G4 therefore constitute an attractive therapeutic target for antitumor therapies based on the stabilization of the structure by synthetic ligands that inhibit overexpressed telomerase. $^{5}$

G4 structures in promoter regions play a dual role in the regulation of transcription: ${ }^{29}$ First, G4 formation can inhibit transcription as the secondary structure can act as a roadblock, stalling polymerase progression. For example, stabilization of the G4 structures within the promoter c-myc by the protein nucleolin leads to the inactivation of this oncogene. ${ }^{30} \mathrm{~A}$ similar behaviour is emulated upon stabilization of oncogenic $\mathrm{G} 4$ (c-myc, c-kit, ras and $\mathrm{BCl}$ ) by synthetic molecules. Secondly, the formation of G4 in promoter regions can increase the levels of transcription. ${ }^{31} \mathrm{G} 4$ are indeed recognized by nucleic acid binding proteins having unwinding capacity and hence favor the recruitment of transcription factors which activate transcription.

The effect of G4 located in the 5'-UTR or in the open reading frame (ORF) regions of mRNA on translation are complex but akin to those exerted by promoter G4 on transcription. G4 motifs are mostly known as translation inhibitors, acting as physical barriers to prevent ribosomal scanning and translocation, ${ }^{32}$ but positive translational regulation has also been described via G4 mediated binding of translation-related factors. ${ }^{32}$ In fact, the effects of G4 deeply lie on their location within the transcript. ${ }^{33}$ One typical example of G4 activity within a long non coding RNAs is the protection of the telomeric structure by the telomeric repeat-containing RNA termed TERRA. TERRA is the telomeric transcript and consist of (UUAGGG) ${ }_{4}$ repeats. ${ }^{34}$ TERRA plays a central role in stabilizing the telomeric structure via interactions with proteins such as TRF2 and the interactions have been shown to rely on the formation of the RNA G4 structure. Another non-protein coding RNA present in people suffering from neurodegenerative diseases, such as amyotrophic lateral sclerosis (ALS) and frontotemporal dementia (FTD), is the hexanucleotide (GGGCCC) repeat expansion (HRE). ${ }^{35}$ This Grich RNA transcript can form G4 structures that sequester important RNA binding proteins leading to the neurodegenerative damages.

Beyond the regulation of the human genome and transcriptome, viral G4 have also been reported to be key regulators of viral replication, transcription and other aspects of viral life cycles. ${ }^{36}$ For example, in HIV-1, G4 have been shown to form both in the RNA genome and in the promoter region of the proviral DNA where they facilitate viral recombination and regulate viral transcription and latency. ${ }^{37}$

\subsection{Targeting}

G4s can exist in a dynamic balance between folded and unfolded states. Their stabilization (or destabilization) by natural molecular partners will directly impact G4-controlled biological processes. The development of synthetic $\mathrm{G} 4$ binders capable of mimicking cellular ligands therefore emerged as a new strategy for gene regulation and therapy. Nowadays, targeting the promoter G4 of oncogenes like MYC by specific ligands results in a down regulation of the gene and hence provides a therapeutic approach towards cancer. Neidle and Hurley reported the first organic molecule, an anthraquinone derivative, specifically designed to interact with $\mathrm{G} 4{ }^{38}$ and inhibit telomerase via the 
stabilization of the telomeric G4. Since then, tremendous efforts have been invested to develop new ligands targeting $\mathrm{G} 4$ for antitumor and antiviral therapies. To date more than one thousand of these molecules were reported. They generally feature an extended aromatic surface for stacking with the G-quartets and positively charged side chains to bind G4 grooves and loops. ${ }^{39,} 40$ Representative organic ligands (inorganic ones will be described below) are bisquinolinium (PhenDC3, 360A) ${ }^{41}$ and pyridine carboxamide derivatives (PDS), ${ }^{42}$ acridine analogs (BRACO-19) ${ }^{43}$ but also natural products such telomestatin (Figure 3). ${ }^{44}$ Amongst them Quarfloxin has progressed to phase II clinical trials for the treatment of neuroendocrine/carcinoid tumours. ${ }^{45}$ Beyond the search for novel drug candidates, the identification of G4 binders capable of tracking G4 is also of high interest to better understand their biology. The cellular localization and dynamics of $\mathrm{G} 4 \mathrm{~s}$, as well as the identification of their exact $\begin{array}{lllll}\text { structures is } & \text { indeed largely el }\end{array}$

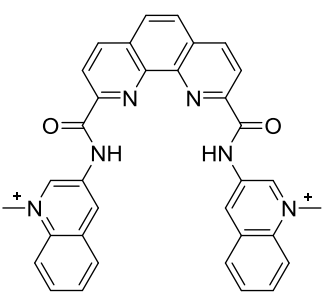

$\mathrm{PhenDC}_{3}$

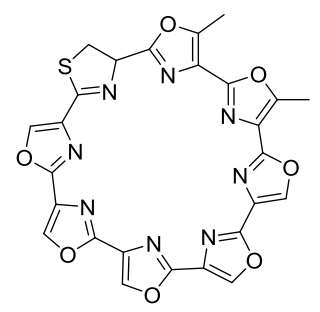

Telomestatin

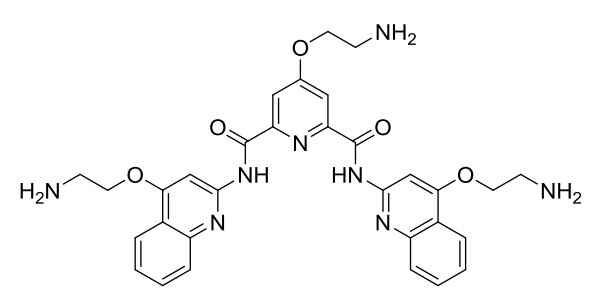

PDS

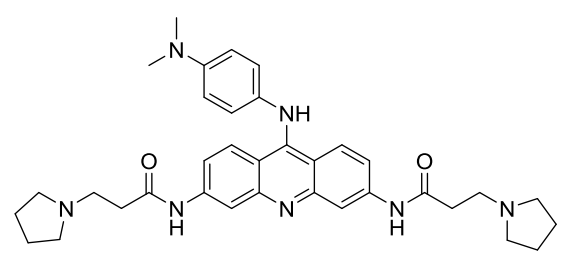

BRACO-19

Figure 3. Structure of representative organic G4 ligands.

It must be emphasized that G4 ligands can also exhibit antiviral activities when subjected to cells infected by viruses whose life cycle depends on G4-mediated mechanisms. ${ }^{46,47}$ Finally, the targeting of RNA deserves some comments. Because of the similarity between RNA G4 and DNA G4, selective targeting of RNA G4 is extremely challenging. Only a few compounds (organic ligands derived from PDS) have been shown to bind preferentially RNA G4 ${ }^{48}$ A quinazoline compound was also shown to interact specifically with the $\mathrm{G} 4$ of the Human vascular endothelial growth factor and impeded tumor cell migration. ${ }^{49}$

Overall and because of the conformational similarity between $\mathrm{G} 4 \mathrm{~s}$, most of the ligands can bind multiple G4 targets and discriminating single G4 targets is one of the current challenges in the field. The central goal of several research groups has now shifted toward the identification of ligands which, beyond binding affinity and selectivity, will be equipped with increased functions such as the ability to react with the $\mathrm{G} 4$ structure and inorganic complexes are particularly fitted to this end, as demonstrated in the following sections. 


\section{Factors governing the interaction with metal complexes}

Due to their importance in controlling the telomere maintenance and expression of proto-oncogenes G4 are considered promising targets for the design of new chemotherapeutic agents. As a consequence an exponential number of G4 binders (inorganic and organic) have been developed during the past decade. The success of the inorganic platform for designing G4 ligands lies in a highly modular synthesis. It allows for the preparation of libraries of compounds, while distinct metal ions can be introduced to control both the central charge and the overall geometry of the complexes. The rational design of a G4 ligand is based on i) the identification of distinct local interaction sites, usually common to other nucleic acids (first level) and ii) the consideration of the global, folded, structure (second level).

\subsection{Local sites of the interactions}

The local sites are the chemical functions naturally present in G4 that can be targeted: The first obvious ones are the negatively charged phosphates. A direct coordination is difficult to control, but ionic interactions are often exploited for improving the affinity of complexes with $\mathrm{G} 4$. The metal can be involved in such ionic bridges, as exemplified by platinum supramolecular cages in interaction with G4 that show metal ions positioned in the close vicinity of the upper phosphates. Alternatively and very often the ligand is appended by positively charged groups, which are directed towards the phosphates. A last strategy for targeting phosphates consists in introducing $\mathrm{H}$-bond donors in the ligand. Amine moieties for instance can establish a $\mathrm{H}$-bond network with phosphates (acceptors), stabilizing the ligand-quadruplex complex. A second favored site for the interaction is the guanine ring, which is omnipresent in $\mathrm{G} 4$ forming sequences. $\pi$-stacking interactions with guanines are widely explored for designing G4 ligands, and not surprisingly almost all of these ligands feature large aromatic moieties. The $\mathrm{N}-7$ of the purines (guanines, adenines) is also a potential coordination site, as largely demonstrated for duplex-cisplatin adducts. Such coordination, known as platination, is also observed in G4. In addition, direct coordination to heavy toxic metals such as mercury was observed with thymines, as illustrated by the thymine dimer formed within the $\mathrm{G}_{3} \mathrm{AATG}_{3} \mathrm{CAG}_{3} A \mathrm{ATG}_{3}$ sequence. ${ }^{50}$ 

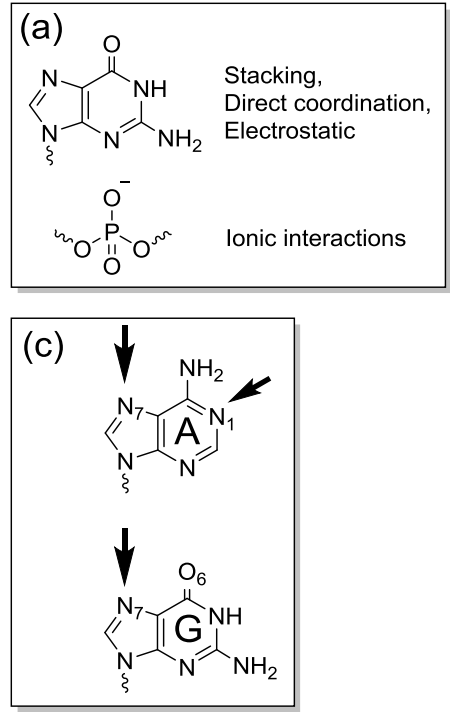

(b)

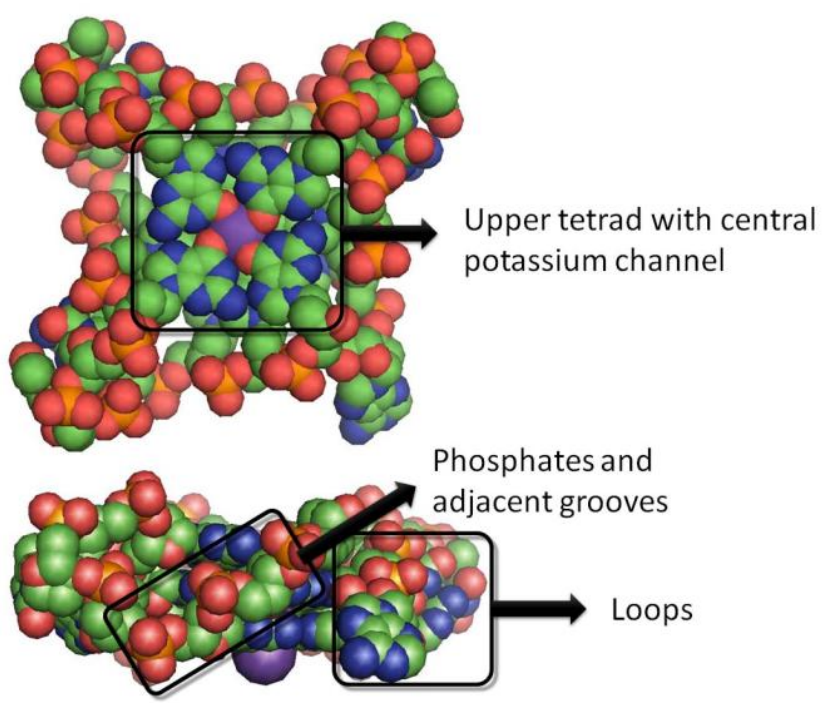

(d)<smiles>C[I+](C)CCCN1C(=O)c2cccc3cccc(c23)C1=O</smiles>

Benzo[d,e]isoquinoline appended cyclometallated $\operatorname{Ir}(\mathrm{III})$ complex

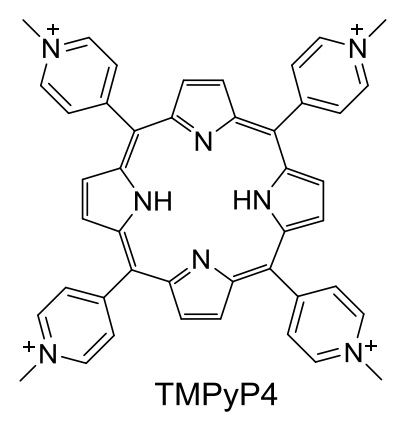

Figure 4. Main sites of interaction: (a) local sites; (b) global sites exemplified on the structure of the parallel human telomer quadruplex (pdb entry 1KF1); (c) Main platination sites; d) Structure of compounds that interact through groove binding and/or stacking (see the text)

\subsection{Global sites of the interactions}

The second level of interaction is based on the peculiar 3-dimensional structure of G4 DNA: presence of G-quartets, specific loops and grooves, potassium channel, etc (Figure 4) ... The specificity of the ligand for quadruplexes (and ultimately for a given topology) versus duplex DNA is largely dependent on these considerations. While some empirical rules can apply for designing specific G4 ligands, one has to emphasize that the polymorphism of these structures drastically complicate the task. Of course multitopic ligands, e.g. capable of targeting several sites at the same time, will be the most selective. Hence the incorporation of large aromatic rings (fused or distinct but coplanar aromatic rings) into the ligand provides it with the ability to stack over the upper tetrad ("top stacking") and hence gives a facile way for discriminating quadruplex vs. duplex. The tetrad is also characterized by a central hole, which defines a channel when several G-quartets are stacked one on each other. This channel is naturally occupied by structuring alkali metal ions, which are bonded with the 06 of the guanines and sandwiched between consecutive tetrads. As for natural alkali metals, the top of the channel is a favored site of interaction for the electropositive metal ion of the G4 ligands. It is therefore not surprising that top stacking of complexes is often associated with the positioning of the central metal ion above the potassium channel. The interactions with the loops and grooves are in 
general harder to predict, but often observed in multitopic ligands in addition to top stacking. The benzo[d,e]isoquinoline appended cyclometallated $\operatorname{Ir}(I I I)$ complex is an example of compound that binds exclusively through groove interactions. ${ }^{51}$ The archetype $\mathrm{TMPyP}_{4}$ is an interesting example of a complex that exhibits two distinct binding modes: Either outside groove binding mode or top stacking. ${ }^{52}$ 


\section{Main families of molecular complexes}

Several main classes of ligands have emerged in the literature as efficient G4 binders. Only the most common scaffolds that bind through electrostatic interactions (mainly $\pi$-stacking, ionic bridges) will be discussed in this section. Inescapable ligands are porphyrins, which show a large aromatic planar structure due to the conjugation of the four pyrrole rings. The meso functions can be functionalized by positively charged groups to improve the affinity towards $\mathrm{G} 4$, while the pyrroles can be substituted by isoindoles to increase the aromaticity (phthalocyanines). Other common ligands are salphens, which are tetradentate Schiff bases featuring a central phenylenediamine ring connected to two peripheral phenol moieties via imine linkers. Their success lies in their high affinities for G4 (the three aromatic rings allows for a top $\pi$-stacking), combined with an easy and versatile synthesis. As an example lateral cationic chains of various lengths or connected at distinct positions can be introduced into the ligand to establish qualitative structure activity relationships (QSAR). The third widely represented family is that of pyridyl-based ligands. Pyridines are neutral aromatic ligands, enforcing a highly positively charged metal site. They can be largely extended (quinolines, acridines ...) for improving stacking, connected together (bipyridine, terpyridines ...) to increase the denticity and of course diversely functionalized in order to add anchoring sites.

\subsection{Salphen}

Salphen ligands (and their analogues) are versatile and very abundantly described compounds due to their easy synthesis and coordinating chemistry compatible with a wide variety of metal ions. The ability to easily modulate parameters such as scaffold functionality or geometry has contributed to the success of this family and the establishment of a large library of compounds whose 1-22 are representative (Figure 5). Free ligands are not able to stack and stabilize G4 due to their flexible geometry. However, the presence of a metal blocks the geometry and favours $\pi$ stacking with G4. Among the many synthesized complexes the $\mathrm{Ni}(\mathrm{II}), \mathrm{Cu}(\mathrm{II})$ or $\mathrm{Pt}(\mathrm{II})$ ones, with a square planar geometry around the metal ${ }^{53-55}$ have strong affinities towards G4 compared to V(IV)O complexes with square base pyramid geometry or distorted trigonal bipyramidal like for $\mathrm{Zn}$ (II). ${ }^{55,56}$ In addition, a high quadruplex (mainly hTelo and c-myc) / duplex selectivity for the square planar complex $\left(\mathrm{K}_{\mathrm{D}}=\right.$ 0.1-10 $\mu \mathrm{M})$ was noticed with respect to duplexes $\left(K_{D}=2 \mu \mathrm{M}\right)$. The addition of cationic side arms to the ligands (quaternary amines, alkyl imidazolium, cyclic amines which may eventually be protonated at physiological $\mathrm{pH})^{57-60}$ increases the affinity towards $\mathrm{G} 4$ by establishing electrostatic interactions with the negatively charged grooves and loops of the G4. The first example of such a salphen metal complex $(6,12)$ interacting with a G4 was described in 2006 by Vilar et al. ${ }^{61}$ These metal-salphen interactions with $\mathrm{G} 4$ are often studied by docking and show that the aromatic planar surface of the complex is stacked on the top terminal part of the tetrad with the metal lying directly above the central ion channel. This mode of quadruplex binding was also confirmed by two X-ray diffractions structures of $\mathrm{Ni}(\mathrm{II})$ and $\mathrm{Cu}(\mathrm{II})$ salphen complexes (12-13). ${ }^{61}$ Both metal complexes stack directly onto the $3^{\prime}$ end G-quartet face of hTelo, with one side chain extending towards a quadruplex groove.

It can also be very interesting to use Pt(II) as a metal because the corresponding complexes may be highly emissive. This was used to investigate the DNA binding profile and study the cellular uptake and localization by confocal microscopy. ${ }^{56}$ These emissive properties can also be shown by salen / 
salphen based series of fluorescein derivatives with $\mathrm{Ni}(\mathrm{II})$ and $\mathrm{Pd}(\mathrm{II})$ centers (23-24). The enhanced planarity along with the fluorescent handle, makes the complexes well suited for G4 stabilization. ${ }^{62}$

Very recently, Vilar et al. showed that an octahedral Pt(IV) salphen complex (5) with a poor affinity towards G4 DNA could be converted into a square planar Pt(II) salphen (upon addition of glutathione or ascorbic acid, both common reducing agents in vivo) with good G4 affinity, leading to the first redox-trigged G4 binder for hypoxic tumor cells. ${ }^{63}$

Finally, a new family of salphen complexes (25) based on octahedral Co(III) with one of the $\mathrm{NH}_{3}$ axial ligand lying above the $\mathrm{K}^{+}$ionic channel has been developed and binds to the external tetrad of the $\mathrm{G} 4$ with both non covalent $\pi$ stacking, hydrogen bonding and electrostatic interactions. These complexes also have the ability to template the formation of $\mathrm{G} 4$ from the unfolded sequence. ${ }^{64}$
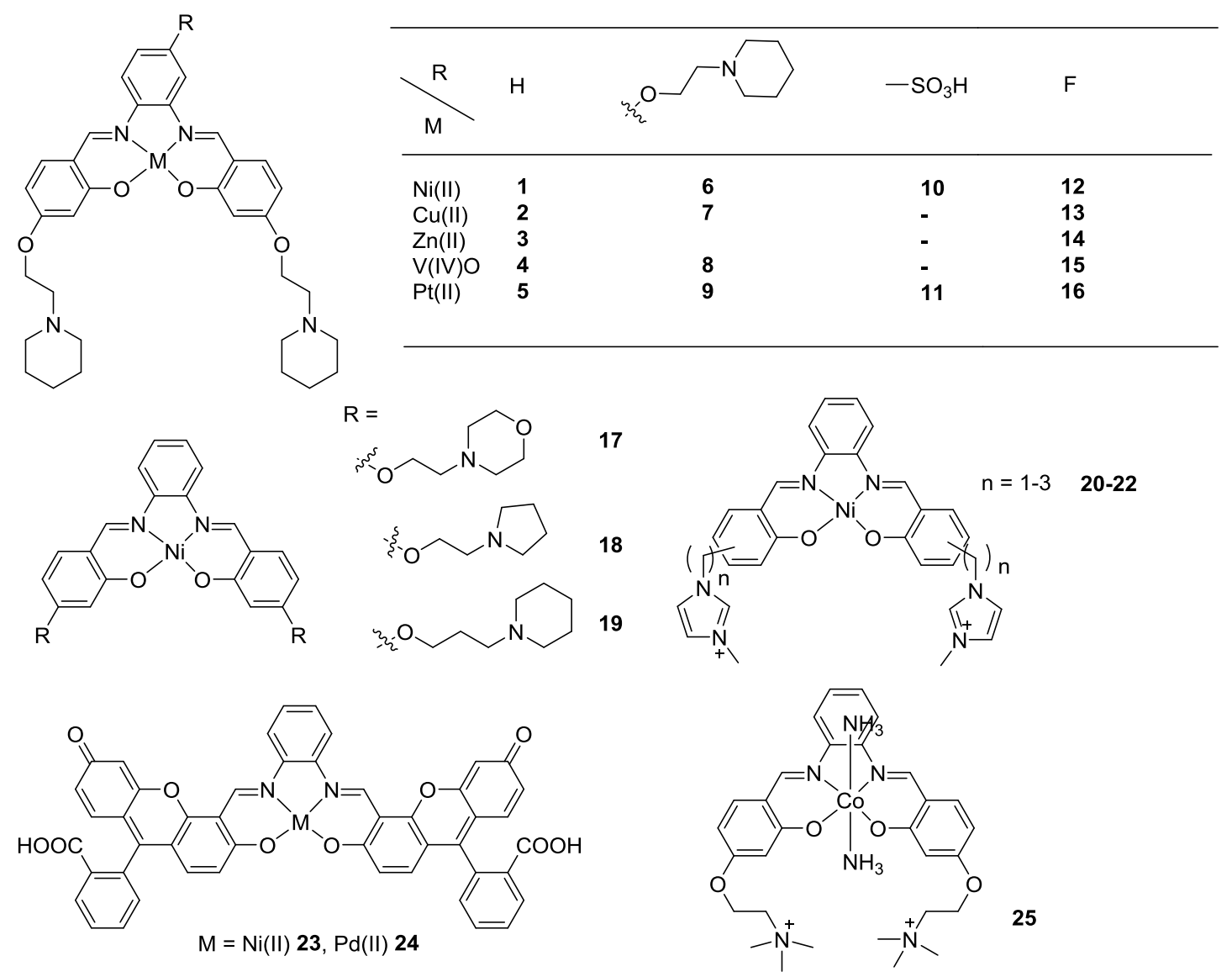

Figure 5. Representative examples of $\mathrm{G} 4$ binders based on metal-salphen complexes.

\subsection{Porphyrins}

Most of the metal complexes interacting with G4 do it through non-covalent binding and porphyrins have been extensively studied as $\mathrm{G} 4$ ligands because of their appropriate size and symmetry. Among them, the cationic free base tetra-(N-methyl-4-pyridyl)porphyrin (TMPyP4, Figures 3 and 6) was first reported by Hurley's group in 1998 to interact with G4 and inhibit telomerase in a cell-free system. ${ }^{65 \text {, }}$ 
${ }^{66}$ In accordance with these results, TMPyP4 inhibits proliferation of various tumor cells including human pancreatic, breast and prostate carcinomas. ${ }^{67,68}$ Even if an $\mathrm{IC}_{50}$ value of $8 \mu \mathrm{M}$ for TMPyP4 was obtained, metal complexes were also synthesized because the central ion has a significant effect on the level of biological activity. ${ }^{66,69} \mathrm{~A}$ large series of porphyrin TMPyP4 complexes with many metals has been studied including square planar $\mathrm{Ni}(\mathrm{II}), \mathrm{Cu}(\mathrm{II})^{69-71}$ pyramidal $\mathrm{Zn}(\mathrm{II})^{72}$ or octahedral $\mathrm{Co}(\mathrm{III})$, $\mathrm{Mn}(\mathrm{III})^{70,73,74}$ (26-31). All these systems stabilize hTelo G4 and inhibit in vitro telomerase activity through $\pi$ stacking and the presence of cationic charges. In all the cases, the mode of interaction with the G4 has been concluded to be top stacking with a complex: quadruplex binding stoichiometry found to be $2: 1$. Some lanthanide complexes were also synthesized but were found to be less active towards $\mathrm{G} 4$ mainly because these latter metals lie above the main plane of the ligand and induce lower $\pi$ stacking interactions with the quartet. However the introduction of a positively charged gold(III) ion with a square planar geometry (no axial ligand on the metal) afforded goldporphyrins endowed with a noticeably higher affinity for G4 DNA compared to divalent metals. ${ }^{75}$

Beyond the choice of the central metal ion in the porphyrin, the nature and number of cationic substituents at the meso position of the aromatic macrocycle are also determining factors for the affinity and selectivity towards G4. When the initial cationic TMPyP4 is modified by the replacement of one or two methylpyridinium groups by one or two 4-aminoquinoline moieties (32-35), in order to increase the cell penetration, the $\mathrm{Mn}(\mathrm{III})$ and $\mathrm{Ni}(\mathrm{II})$ compounds present inhibition of telomerase with $I_{50}$ values in the micromolar range. ${ }^{70}$ Moreover, a manganese(III) porphyrin combining a central aromatic core and four flexible cationic arms (36) is able to discriminate between quadruplex and duplex DNA by 4 orders of magnitude. The bulky cationic substituents surrounding the aromatic core, which preclude a close interaction with the double-stranded DNA structures, could be responsible for its poor affinity for duplex DNA. The very high affinity for the four-stranded DNA structure originates from a combination of interactions between the G-quartet and the porphyrin core on the one hand, and between the grooves and/or loops and the flexible cationic arms on the other. ${ }^{73}$

\subsection{Phthalocyanines and corroles}

Phthalocyanines are also very interesting ligands because, according to computational modeling, they have especially good shape complementarity with G4 DNA due to their more extended planar $\pi$ system than porphyrins. A series of water-soluble cationic $\mathrm{Zn}$ (II) and $\mathrm{Ni}(\mathrm{II})$ phthalocyanine derivatives $(37,39)$ were designed ${ }^{76,77}$ and act as telomerase inhibitors $\left(I C_{50}=20-620 \mathrm{nM}\right)$. For example, octacationic quaternary ammonium zinc(II) phthalocyanine $\mathbf{3 7}$ is a very good G4 DNA stabilizer that can increase polymerase pausing in the TRAP assay by stabilizing the G4 structure formed in low $\mathrm{K}^{+}$ concentration buffer. It can also induce intramolecular G4 structure transitions from the antiparallel to parallel form, and the parallel structure formation in cation-deficient conditions. ${ }^{76}$ The number of positive charges on the phthalocyanine derivatives is a key point and was varied from four to eight to evaluate the effect of electrostatic interactions with phosphate groups of G4. In this way, it has been shown that more positive charges on phthalocyanines are associated with more efficient inhibition of telomerase activity. ${ }^{77}$ The role of the metal is also important. When the coordination metal is nickel(II), the phthalocyanine may adopt a geometry that is more favorable for binding to the G4 and the $\mathrm{IC}_{50}$ of the $\mathrm{Ni}(\mathrm{II})$ complex is 10 -fold lower than that of $\mathrm{Zn}$ (II). 
Among all the ligands interacting with c-myc quadruplex described in the literature, Luedtke's group synthesized two series of cationic $\mathrm{Zn}$ (II) phthalocyanines bearing amido and guanidinium substituents (40-46) that $^{78,79}$ revealed apparent dissociation constants ranging from 20 to $200 \mathrm{nM}$, which are the smallest values reported to date. Binding interactions are driven mostly by electrostatic interactions and for the latter compounds, these results indicate that the guanidinium groups can form hydrogen bonds with the phosphate groups and/or bases in DNA. Approximately 500-fold lower affinities for duplex and single stranded DNA were also observed.

Corrole ligands that can stabilize high-valent metals have also been studied as G4 binders because they may strengthen the interaction between the corrole scaffold and G4. So $\mathrm{Cu}$ (III) and $\mathrm{Mn}$ (III) quaternary ammonium corroles were synthesized. ${ }^{80,81}$ Among them, the manganese (III)-corrole 47 with three methyl-pyridinium substituents at the meso position exerts a better stabilization effect towards the G4 structure ( $\mu \mathrm{M}$ range). The five-coordinate $\mathrm{Mn}$ (III) ion deviates slightly from the mean plane of the inner pyrrole nitrogen atoms with a significant "saddle"-type distortion of the corrole rings which hint at $\pi$-stacking interactions with DNA base pairs. Moreover, both $\mathrm{Cu}(\mathrm{III})$ and $\mathrm{Mn}$ (III) methylpyridinium corroles tend to induce the human telomeric sequence to form hybrid G4 structures. 


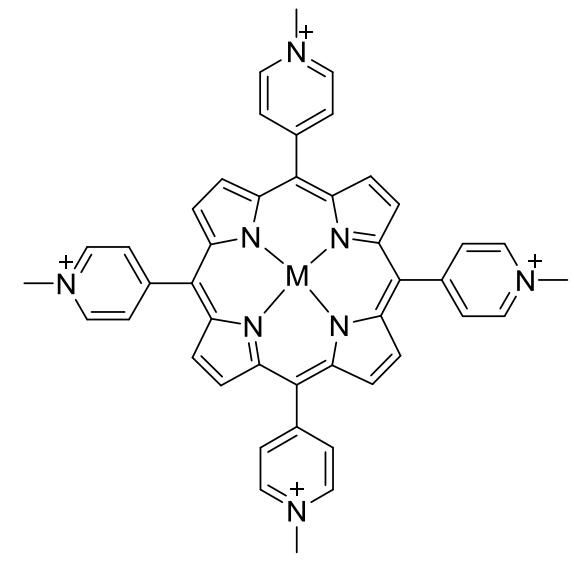

$\mathrm{M}=\mathrm{Ni}(\mathrm{II}) 26, \mathrm{Cu}$ (II) 27, Zn(II) 28

Co(III) 29, Mn(III) 30, Au(III) 31

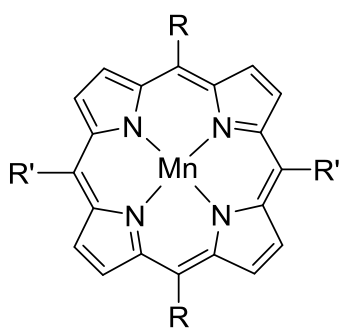<smiles>[R]#C[Y9]1([H])ccc(NC(=O)CCc2ccc[n+](C)c2)cc1</smiles>

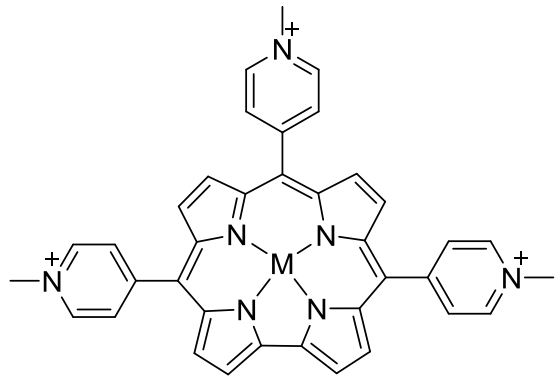

$M=M n(I I I) 47, C u(I I I) 48$ 36

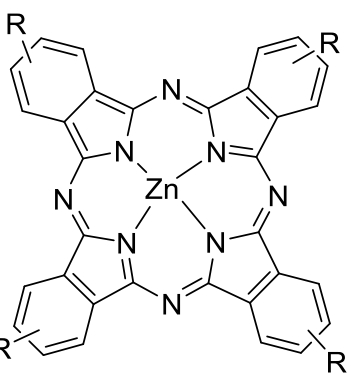<smiles>[R]=COC(C[N+](C)(C)C)C[N+](C)(C)C</smiles>
$\left.\underbrace{N}_{\mathrm{O}}\right|_{n} ^{\mathrm{NH}_{3}} \quad \mathrm{n}=1-4$ $\sum_{\mathrm{R}^{\prime}}^{-\xi-\mathrm{NH}}=\mathrm{NH}_{+}^{\mathrm{R}^{\prime}} \mathrm{R}^{\prime}=\mathrm{H} 44, \mathrm{iPr} 45, \mathrm{cC} 6 \mathrm{H} 1146$

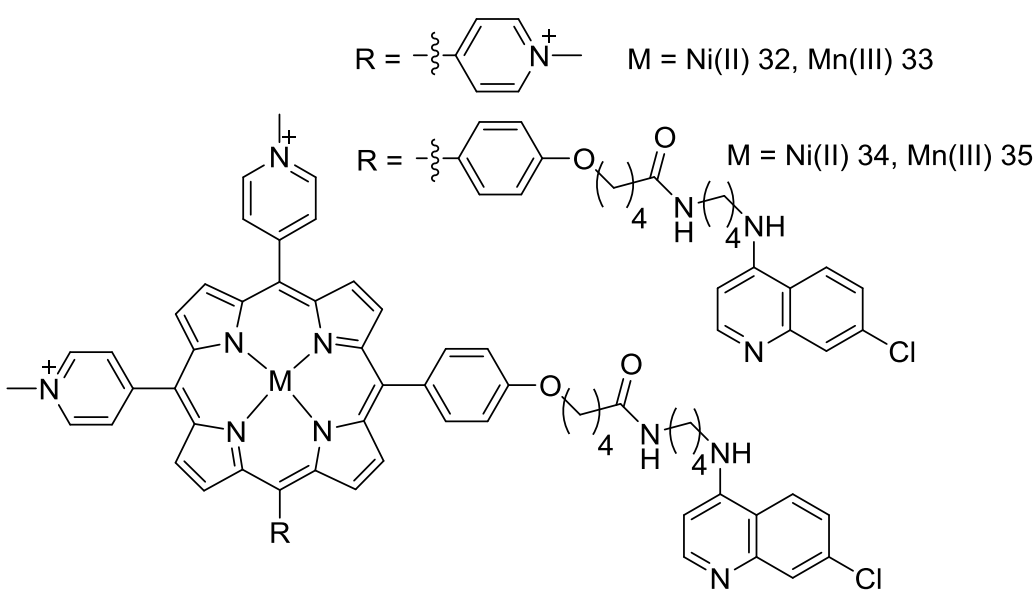

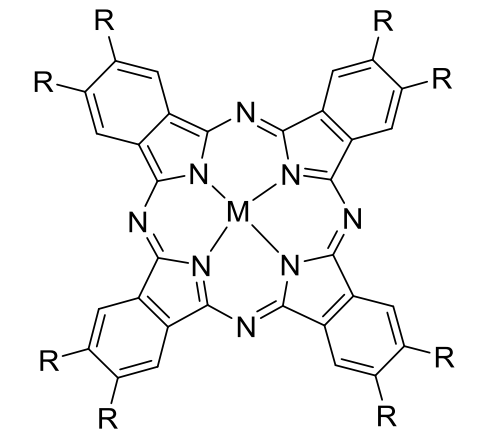<smiles>[R][14CH2][14CH2]OCC[N+](C)(C)C</smiles>

$M=Z n(I I) 38$, $\mathrm{Ni}(\mathrm{II}) 39$

$$
46
$$


structures (Figure 7). A large number of $\mathrm{Cu}(\mathrm{II}), \mathrm{Zn}(\mathrm{II})$, and Pt(II) complexes have been synthesized with square planar and square-based pyramidal geometries. ${ }^{8,82,83}$ It is assumed that the metal ion increases the ability of the ligand to display $\pi-\pi$ stacking interactions with the external G-tetrad and can replace a metal cation involved in the G-tetrad stabilization. But since the geometry favored around the metal is square planar, the studies focused more on Pt(II) complexes. However, even with the addition of side chains with cyclic amine head groups on the ligand, terpyridine Pt(II) complexes shows only a modest selectivity ( 1 order of magnitude) for quadruplex (particularly c-myc), versus duplex DNA. ${ }^{84}$ Moreover, in order to avoid the platination of adenine bases located in the loops, the extension of the aromaticity of the ligands has been developed (dibenzoterpy, bis(benzimidazole)pyridine) and these modified terpyridine complexes show increased affinities towards G4. ${ }^{83}$ For example, a series of platinum(II) complexes containing 2,6-bis(benzimidazol-2yl)pyridine (bzimpy) (60-63) and 2,6-bis(pyrazol-3-yl)pyridine scaffolds with amine side chains (64-65) were found to display high selectivity towards c-myc G4 DNA and not duplex DNA. They also showed significant inhibition of c-myc gene transcription in cultured cells, presumably through the stabilization of the G4 structure. ${ }^{85}$

$\mathrm{Pt}$ (II) terpyridine complexes have also been synthesized where the fourth coordination position can be modulated (66-68). The presence of a labile chloride ligand allows the possibility of direct coordination between the complex and G4 (platination), but if it is replaced by $\sigma$-alkynyl ancillary ligands which contain peralkylated ammonium pendants or tertiary amine side chains, a selectivity for quadruplexes over duplexes is observed, and cytotoxic activity of Pt(II) complexes are noticable, with $\mathrm{IC}_{50}$ value $<0.62 \mu \mathrm{M}$ after $48 \mathrm{~h}$ incubation. ${ }^{86}$ 

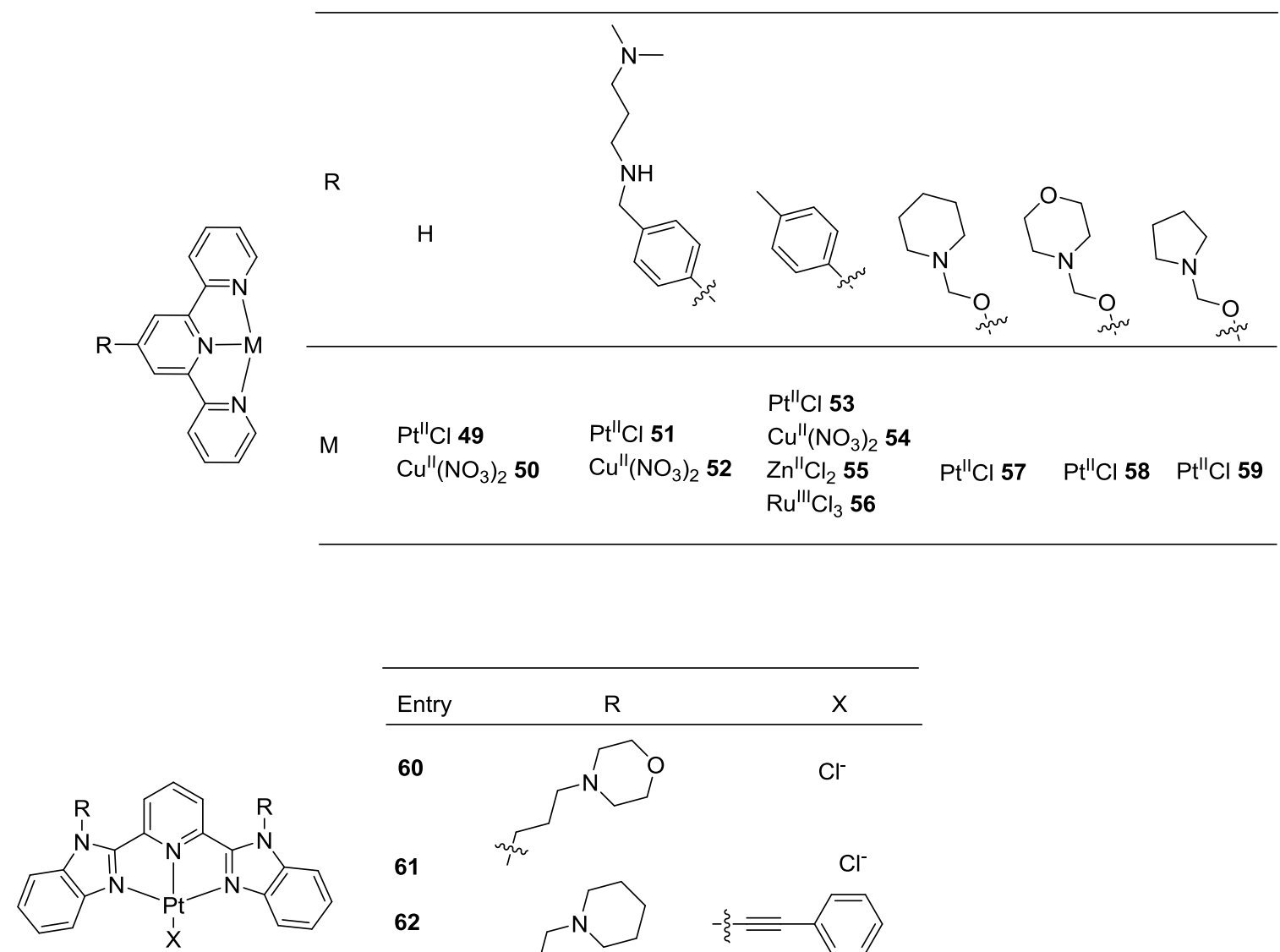

\begin{tabular}{lll}
\hline Entry & $\mathrm{R}$ & $\mathrm{X}$ \\
\hline
\end{tabular}
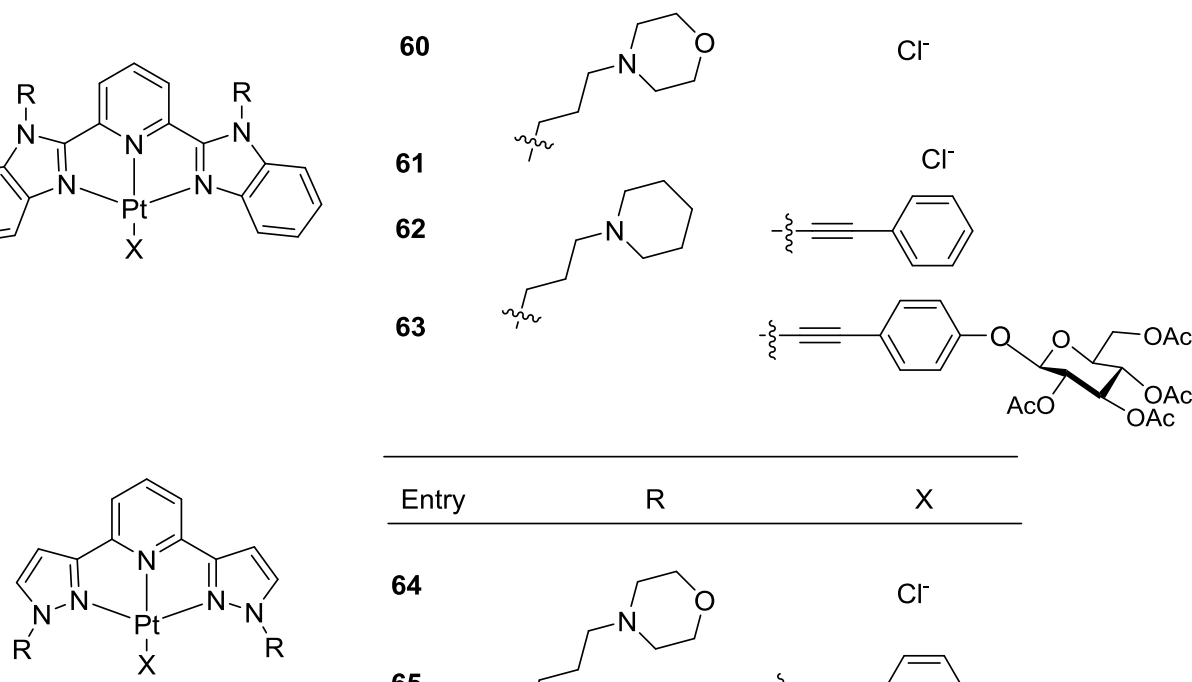

64

$\mathrm{Cl}^{-}$

65<smiles>CCCCN1CCOCC1</smiles>
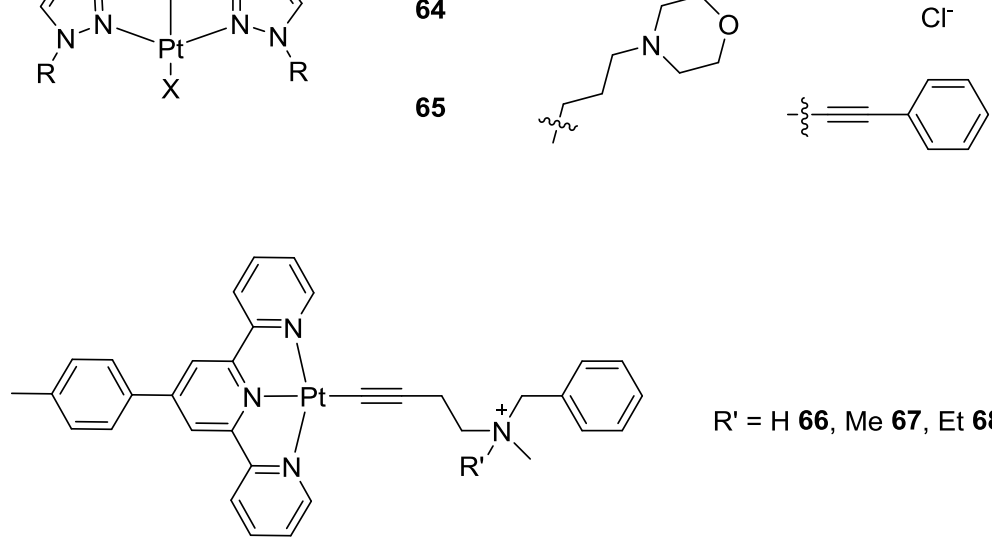

$R^{\prime}=H$ 66, Me 67, Et 68

Figure 7. Representative examples of G4 binders based on metal-terpyridines complexes.

\subsection{Phenanthrolines and derivatives}

More complexes based on other polypyridyl ligands (in particular phenanthrolines and their derivatives) have been studied as G4 ligands. In these families, Pt(II) is the most representative metal 
because it imposes a square planar geometry. A poor G4 ligand like phenanthroline (phen) can be turned into an effective binder upon proper metal ion coordination, and the two simplest compounds $\mathrm{Pt}(\text { phen })_{2} \mathbf{6 9}$ and $\mathrm{Pt}(\mathrm{bpy})_{2} \mathbf{7 0}$ exhibit high stabilization for G4 DNA, with the former possessing higher capability due to its greater planarity (Figure 8). ${ }^{87}$ Mono-substituted carboxamide phenanthrolines (71-74) used as tridentate ligands to coordinate to platinum(II) have also been prepared. The interactions between these complexes and DNA (both duplex and quadruplex) have been studied by FRET methods and show high selectivity for quadruplex vs duplex DNA. ${ }^{88,89}$ In order to increase affinity constants with the metal (Pt(II) for example) and avoid the formation of complexes with variable stoichiometry in solution, two phen moieties can covalently be linked through a thioether $(\mathbf{7 5 - 7 6})$ or an amine bond $(\mathbf{7 7}, \mathbf{7 8}) .{ }^{90}$ Interestingly, metal ion complexation remarkably affects ligand-stabilizing effects on $\mathrm{G} 4$, the melting temperature of the folded structure being increased up to $30^{\circ} \mathrm{C}$ at ligand concentrations as low as $1 \mu \mathrm{M}$ in the presence of $\mathrm{Ni}(\mathrm{II})$ and $\mathrm{Cu}(\mathrm{II})$. In line with their G4 stabilizing properties bis-phen complexes are effective inhibitors of telomerase activity, $\mathrm{Ni}(\mathrm{II})$ complexes being effective in the sub-micromolar range.

Modified phen ligands like dppz (dppz for dipyridophenazine) are known to be good metallointercalators of double-stranded DNA. ${ }^{91} \mathrm{Pt}(\mathrm{II})$ complexes bearing dppz or substituted dppz ligands also bind to G4. ${ }^{92}$ The tightest binding was obtained from the organometallic water-soluble $\mathrm{Pt}(\mathrm{II})$ complex $\mathbf{7 9}$ coordinated to a dppz and a phenylpyridine ligand which inhibited human telomerase in vitro with an $\mathrm{IC}_{50}=760 \mathrm{nM}$. The binding mode with G4 DNA operates through a classical external top stacking with a binding affinity of $\sim 10^{7} \mathrm{M}^{-1}$.

Increasing the size of the $\pi$-surface compared to bipyridine platinum(II) complexes affords greater binding affinity and selectivity for G4 over duplex DNA structures. So $\pi$-extended naphthylphenanthroimidazole ethylenediamine platinum(II) complexes (81-85) display almost two orders of magnitude binding preference to quadruplex DNA over duplex. ${ }^{93,94}$

Other metals such as ruthenium (III) or nickel (II) have also been chelated with phenanthrolines or derivatives but their affinity with G4 has been recognized to be modest or weak. The mode of interaction is likely to operate via the loops of the structure. 


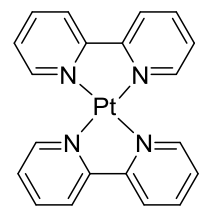

69
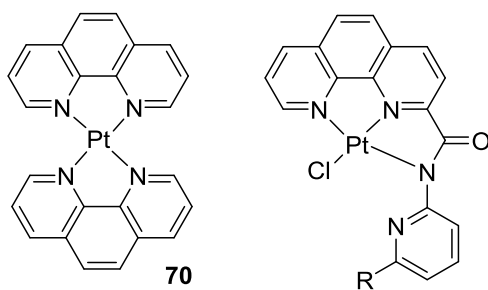

$\mathrm{R}=\mathrm{H} 71, \mathrm{NH}_{2} 72$
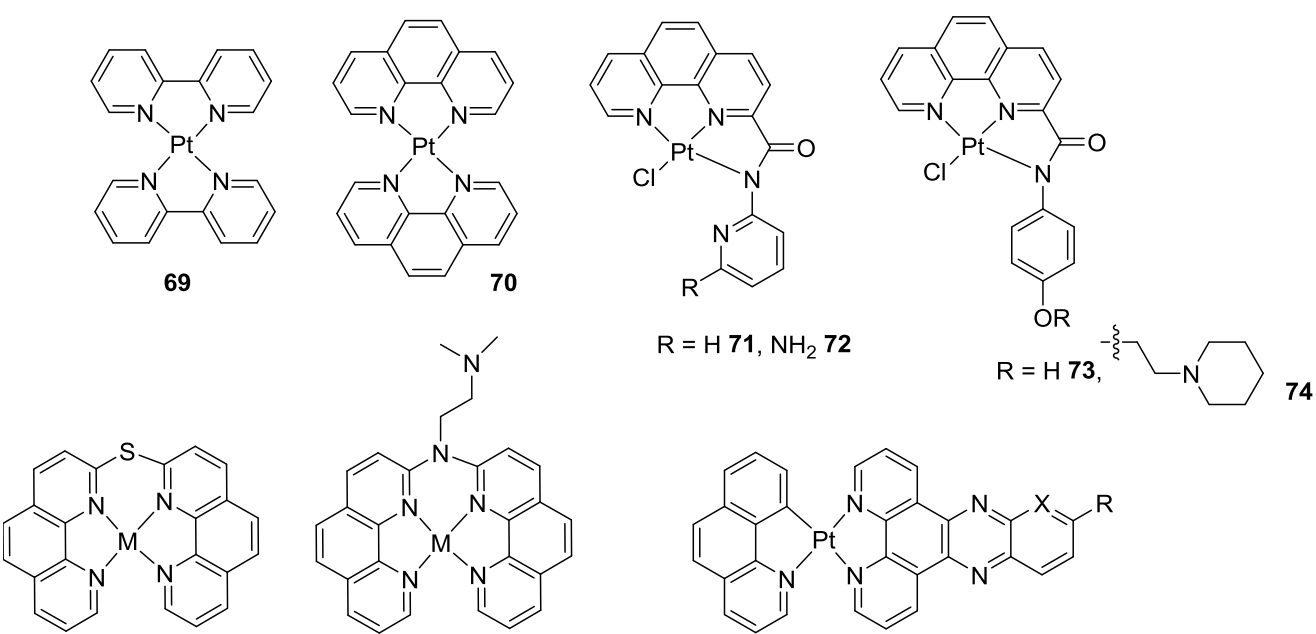

$\mathrm{M}=\mathrm{Cu}(\mathrm{II}) \mathbf{7 5}, \mathrm{Ni}(\mathrm{II}) 76$

$\mathrm{M}=\mathrm{Cu}(\mathrm{II}) \mathbf{7 7}, \mathrm{Ni}(\mathrm{II}) 78$

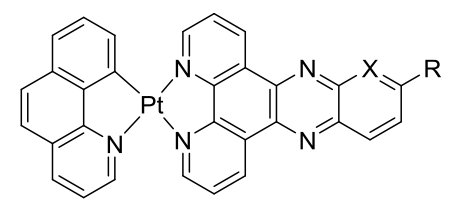

$\mathrm{X}=\mathrm{C}, \mathrm{R}=\mathrm{COO}^{-} 79$

$X=N, R=H 80$

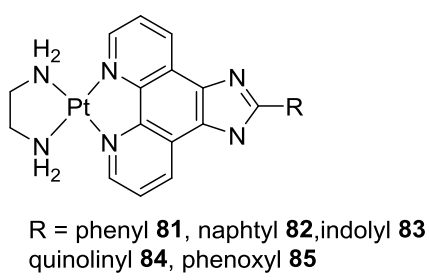

Figure 8. Representative examples of G4 binders based on metal-phenantroline complexes.

\subsection{Octahedral complexes}

Until now, we mostly focused on square planar (or square pyramidal) metal complexes capable of stacking on G4s. Another alternative is to use octahedral metal based complexes with extended $\pi$ aromatic ligands, such as those used for intercalation in duplex DNA. In this context, the most commonly studied metals are $R u(I I)$ and $\operatorname{Ir}(I I I)$. Moreover, such complexes like $\left[R u(b p y){ }_{2}(d p p z)\right]^{2+}(b p y$ = bipyridine, $\mathrm{dppz}=$ dipyridophenazine) also serve as prominent molecular "light switches" for duplex DNA and G4 DNA, ${ }^{95}$ but the luminescent selectivity between two different DNA structures is poor. An important number of polypyridyl ligands with a large planar aromatic area have been tested in order to improve the affinity and selectivity towards G4 DNA. ${ }^{95-99}$ For example, the two ruthenium(II) polypyridyl complexes $\mathbf{8 9}$ and $\mathbf{9 0}$ were explored by means of optical spectroscopy, FRET and polymerase chain reaction (PCR) stop assay indicating that they both have the ability to promote the formation and stabilization of the hTelo quadruplex and exhibit high G4 DNA selectivity over duplex DNA (Figure 9). The TRAP assay further demonstrates that the Ru(II) complexes are potent telomerase inhibitors. ${ }^{100}$ The chirality around the metal center can induce different behaviour of the two enantiomeric forms. Interestingly, the antiproliferative activity of the $\Lambda \mathrm{Ru}(\mathrm{II})$ complex 91 was higher than that of the $\Delta-\mathrm{Ru}(\mathrm{II})$ one and the $\Lambda$ - stereoisomer showed a significant anti-tumor activity in HepG2 cells. ${ }^{101}$

Recently, new tetraazaphenanthrene (TAP) ruthenium(II) complexes 92-93 that can selectively interact with G4 over duplex DNA have been reported, ${ }^{102}$ and are able to perform photo-induced electron transfer (PET) with guanine base. Docking studies and molecular dynamic simulations revealed that this affinity is due to $\pi-\pi$ stacking above the tetrad and interaction with the TTA loop. 
Interestingly, these complexes showed very specific photo-cytotoxic effects, through a mechanism that does not involve the inhibition of telomerase.

In the context of G4 DNA, few cyclometallated iridium(III) complexes have been described. ${ }^{103,104}$ Sleiman and colleagues ${ }^{105}$ have reported complexes $\mathbf{9 4 - 9 8}$ with extended imidazole-phenanthroline ancillary ligands for which luminescence studies revealed its high ability to selectively probe G4 DNA over duplex DNA. These complexes bind with low micromolar affinity to human telomeric and c-myc sequences in a 1/1 complex / quadruplex stoichiometry and thus may allow the direct detection of low levels of G4 DNA in aqueous conditions. Very recently, Elias et coll. ${ }^{106}$ proposed several cyclometallated iridium(III) complexes (100-101) with good affinity towards telomeric G4 DNA and a slight selectivity versus duplex. Due to their oxidizing power in the excited state, they are able to photo-react with DNA, (through a photo-induced charged transfer) with guanine moieties. 


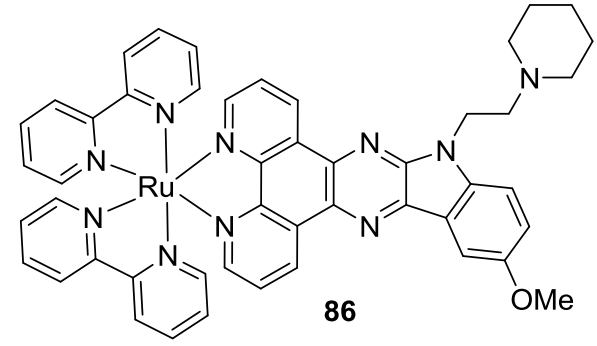

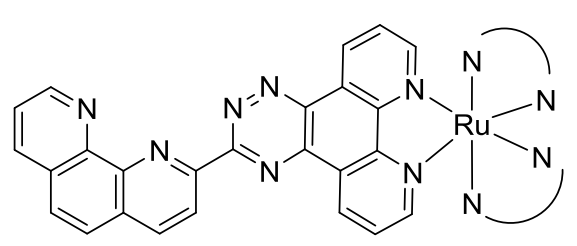

$\left(\begin{array}{lll}\mathrm{N} & & \\ & \text { bpy } & \mathbf{8 9} \\ \mathrm{N} & \text { phen } & \mathbf{9 0}\end{array}\right.$

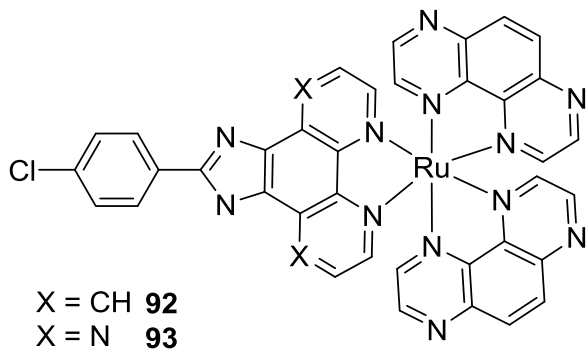

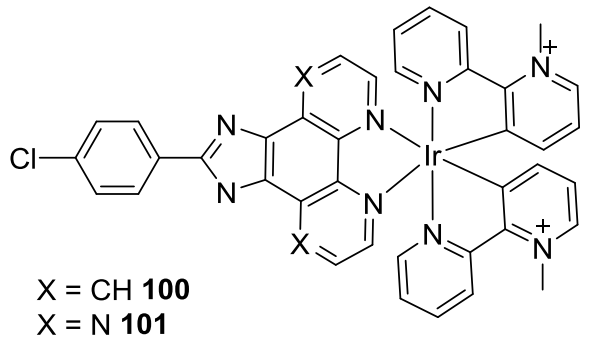

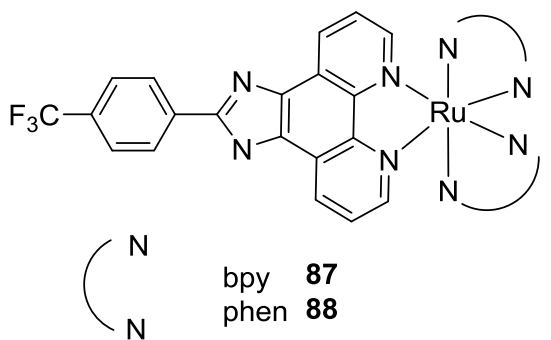

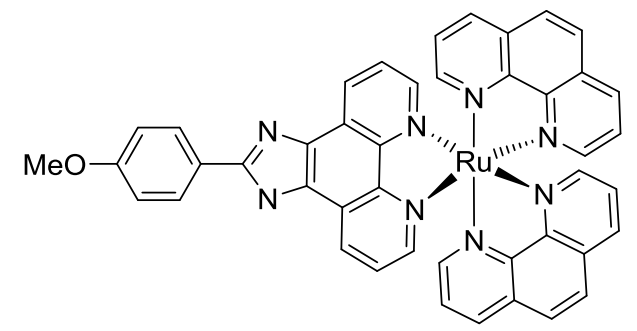

$\Delta \mathrm{Ru}(\mathrm{II}) 91$

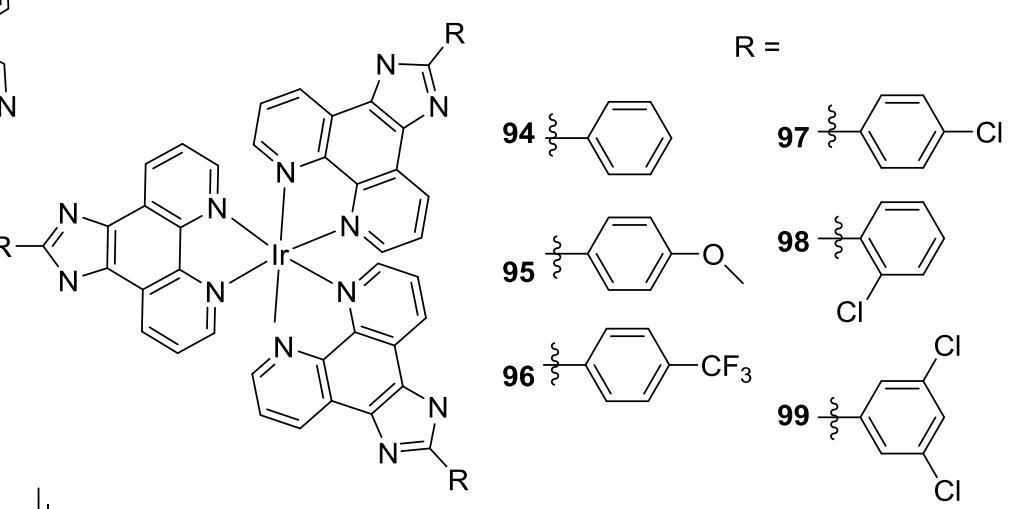

Figure 9. Representative examples of G4 binders featuring an octahedral metal center.

\section{Supramolecular assemblies}

Supramolecular chemistry provides a convenient way to expand the size of a given molecule and control its 3-D shape. Architectures such as cages, cylinders and triangles have been designed for interacting with $\mathrm{G} 4$. The driving force for these assemblies is often metal complexation by pyridyl donors, which implies that the metal should be judiciously chosen. This also implies that local positive charges are present and may contribute to the interaction.

\subsection{Rectangular cages}


One of the first examples of supramolecular assemblies designed for interacting with G4 DNA is the rectangular cage described by Sleiman (Figure 10). ${ }^{93}$ It is based on four 4,4 '-bipyridine ligands wherein the $\mathrm{N}$-donors coordinate in a cis fashion four square planar Pt(en) units (104). The size of the cage $(14 \times 14 \times 3 \AA)$ covers that of the HTelo tetrad $(11 \times 10 \times 9 \AA)$, which leads the authors to suggest that $\left[\mathrm{L}_{4}(\mathrm{Pt})_{4}(\mathrm{en})_{4}\right]^{8+}$ is positioned at the top of the $\mathrm{G} 4$, with the positively charged platinum ions interacting with the negatively charged phosphates. The amines likely interact with the same phosphate, but through $\mathrm{H}$-bonding. It is worth noting that the aromatic rings point orthogonal to the tetrad instead of stacking over it for steric reasons, hence defining the height of the assembly. Notably this ligand exhibits a high affinity ( $\mathrm{K}_{\mathrm{D}}$ of $\left.\mathrm{ca} .10^{-7} \mathrm{M}\right)$ for hTelo and a large selectivity over duplex. Several variants were prepared with the aim of modifying the size of the rectangle (102-105). The 4,4'-bipyridine unit was substituted by longer bipyridine derivatives, ${ }^{107}$ as well as pyrazine ${ }^{108}$ and quinoxaline ${ }^{109}$ moieties, the two latter resulting in smaller cages $(11 \times 11 \times 3$ and $11 \times 11 \times 7 \AA$, respectively). The smallest cage (pyrazine, 105) exhibits affinities one order of magnitude smaller than the parent 4,4'-bipyridine. The largest cage also shows lower affinity than the parent one, showing that the optimal size is efficiently framed within the series. Changes were also made on the auxiliary ligand in order to perturb the $\mathrm{H}$ bonding network (amine instead of ethylenediamine), but the effect is in general more subtle.

The metal:ligand stoichiometry of the cage was also varied by employing fused 4,4'-bipyridine derivatives (106-107). ${ }^{110}$ The metallacycle shows a $\left[\mathrm{L}_{2} \mathrm{Pt}_{2}\right]^{8+}$ structure with alternating $\mathrm{CH}_{2}$ and $\mathrm{Pt}$ ion at the angles. Similarly to the above series the size of the cage was varied ( 10 to $15 \AA$ ) allowing for the identification of an interesting trend whereby the smaller cage (107) gives the lowest affinity for G4 but the highest selectivity over duplexes. Conversely the larger cages (106) give the highest affinity at the expense of the selectivity.

More recently guanosine-substituted terpyridines were employed in combination with platinum or palladium to build sandwich-like metallo-rectangles of general formula $\left[L_{2} M_{2}\right]^{2+}$. 111 Their association with HTelo is mediated by pi stacking interactions between one face of the rectangle and one guanine of the top tetrad, and presumably additional electrostatic interactions with one phosphate. Once again the supramolecular assembly interacts preferentially with G4 than duplex DNA.

\subsection{Cylinders}

Cylinders belong to a major class of supramolecular entities developed in the past to interact with duplex DNA, which gained a renewed interest as G4 binders. Their original success is based on structural similarities with zinc finger domains, which are widely encountered in transcription factors and play a key role in DNA binding and gene expression. Qu et al. reported a bimetallic triple helicate structure $\left[\mathrm{M}_{2}{ }_{2} \mathrm{~L}_{3}\right]^{4+}$ of $18 \times 8 \AA$, based on $\alpha$-iminopyridine chelators and wherein each metal ion (Fe or $\mathrm{Ni}, 108-109)$ lies in an octahedral geometry. ${ }^{112}$ In contrast with the above cages the structures are chiral. The P-enantiomer exhibits a high selectivity towards G4 (20 fold over duplex DNA), in contrast to the M-enantiomer (no stabilization of G4). In addition, the P-enantiomer is capable of converting an antiparallel G4 into a hybrid structure, by interacting strongly with this topology through stacking over the top tetrad and interactions with the loops. Recently the nickel cylinder was shown to promote telomere uncapping in cellulo. ${ }^{113}$

\subsection{Tetrahedral cages}


One of the latest advances in this supramolecular approach was achieved in the $\alpha$-iminopyridine family. The methylene group connecting the phenyl moieties was suppressed, hence rigidifying the ligand. ${ }^{114} \mathrm{~A}$ tetrahedral cage of formula $\left[\mathrm{Ni}_{4}{ }_{4} \mathrm{~L}_{6}\right]^{8+}$ was obtained, whose dimensions are 21 and $7 \AA$ (length and diameter of the six edges, respectively, 110). Notably, the metal ion retains its octahedral geometry, similarly to the cylinders, but herein occupies the apexes. The affinity for htelo G4 was significantly enhanced (one order of magnitude in comparison to 108-109), but its selectivity remains moderate in comparison to duplex DNA.

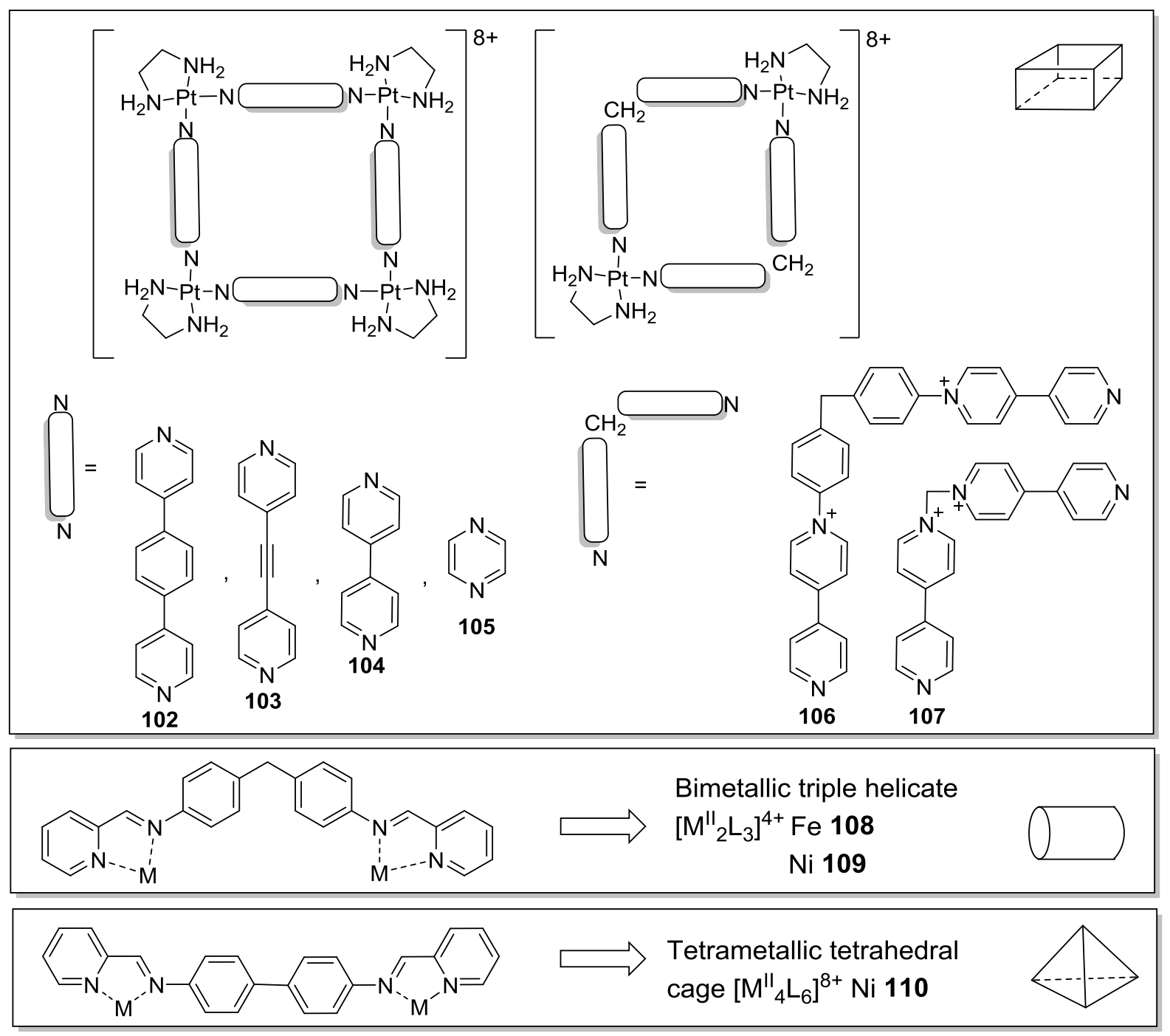

Figure 10. Supramolecular assemblies: Ligands and schematic view of the $3 \mathrm{~d}$ architecture 


\section{Platination}

Platinum-based drugs are widely used in chemotherapy and yet undergo significant developments (see EIBC2728). The first clinically approved drug is cisplatin, which is still used together with new generations of drugs like carboplatin and oxaliplatin. The currently accepted mode of action of cisplatin $\left(\left[\mathrm{PtCl}_{2}\left(\mathrm{NH}_{3}\right)_{2}\right]\right)$ involves an initial exchange of the chlorides by water molecules, followed by the displacement of the water molecules by coordination to the N7 of purines ("platination"), with a preference for guanines. The consequence is an unwinding and bending of duplex DNA that further induces cell death by apoptosis. The fact that the biological target of platinum-based anti-cancer agents is guanine naturally drives research towards the development of platinum complexes for recognition of $\mathrm{G} 4$.

(a)

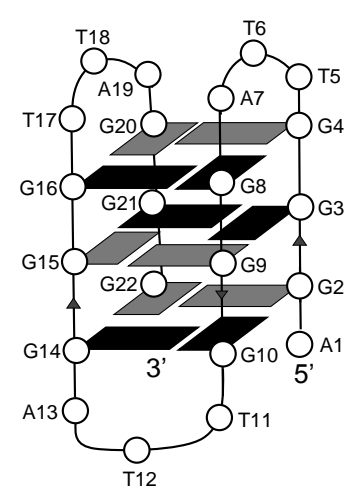

(b)
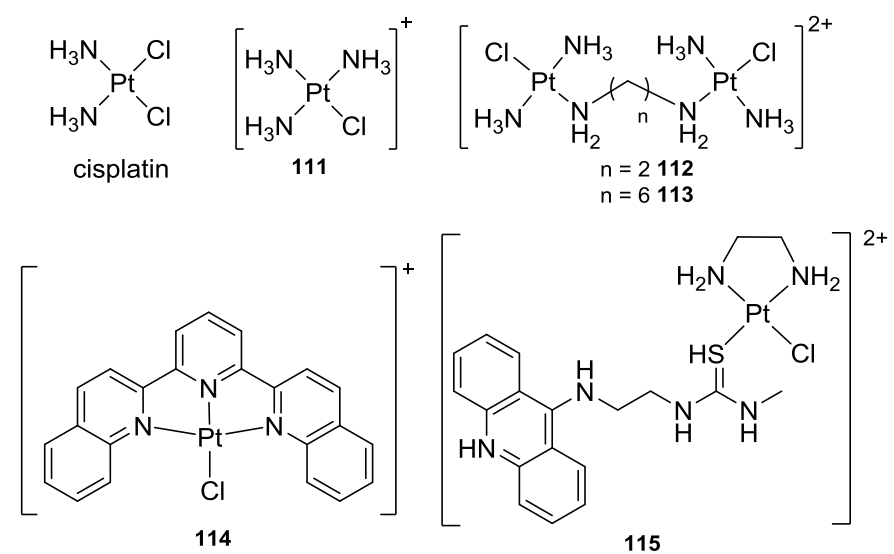

115

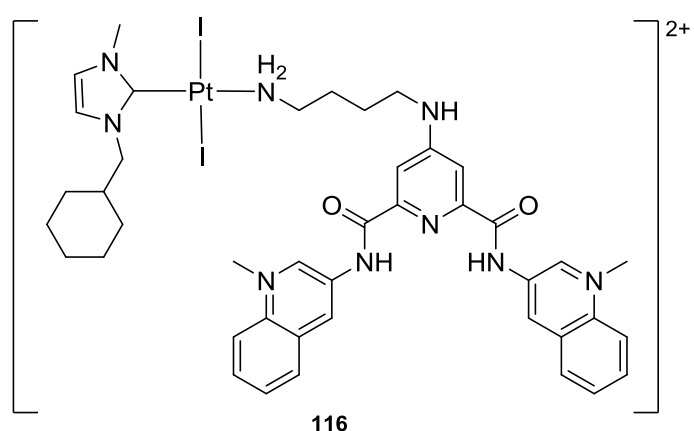

Figure 11. (a) numbering in the antiparallel $G 4$ from $h T e l o G_{3}\left(T_{2} A G_{3}\right)_{3}$ and (b) structure of cisplatin and representative complexes inducing platination in $\mathrm{G} 4$.

In 2001 Bombard et al. investigated the platination of the telomeric sequence $\left(T_{2} G_{4}\right)_{4}$ by cisplatin and its monochloro derivative $111 .{ }^{115}$ The latter was used to identify the reactive sites, without the possibility for cross-linking, which were $\mathrm{G} 9>\mathrm{G} 15>\mathrm{G} 3>\mathrm{G} 21$. Cisplatin, with its two exchangeable sites was capable of cross-linking at both ends of the quadruplex, especially positions G3-G15, in addition to forming monoadducts on $G 9$ and $G 21$ (or G24). With the longer sequence $A G_{3}\left(T_{2} A_{G_{3}}\right)_{3}$ (schematized in Figure 11) cisplatin gives rise to $65 \%$ cross-links at the positions A1-G10 and A13G22. A thorough investigation including different structuring metal salts and the trans isomer of cisplatin allowed the probing of the spatial distribution of the guanines within the G4. Indeed only certain foldings of the quadruplex allows certain cross-links but not others due to an unfavorable spatial separation of the guanines. Hence the position of the cross-linked bases is directly correlated to the folding. This approach lead the author to propose a common antiparallel topology for the 
above longer htelo structure. ${ }^{116}$ This investigation was extended to bis(platinum) complexes 112-113, which induce cross-links at longer interplatinum distances (5.3 - $12.4 \AA$ depending on the length of the linker) in comparison to cisplatin. ${ }^{117}$ The main cross-links are G10-G22 and G2-G14 (only possible for antiparallel folding) and G8-G20 (only for parallel folding and the longer linker) in this case, suggesting a possible interconversion of different conformers in solution for $A G_{3}\left(T_{2} A G_{3}\right)_{3}$, whatever is the structuring cation.

Lately the same quadruplex (Figure 11) was platinated by mononuclear terpyridine platinum complexes that exhibit a single exchangeable site and hence lack the ability to cross-link DNA $(\mathbf{4 9}, \mathbf{5 3}$, 114). ${ }^{118}$ Two preferential platination sites were identified on the antiparallel quadruplex, which differ from the above ones: A7 and A13, both located in loop regions. The aromaticity of the terpyridine was expanded by adding phenyl moieties, leading to an interesting trend whereby platination by the less sterically demanding complexes $\mathbf{4 9}$ occurs at A7 (most reactive), while for tolyl-terpyridine $\mathbf{5 3}$ it is observed at $\mathrm{A} 13$ (most accessible). The palladium derivatives were also investigated, showing a faster ligation to $\mathrm{G} 4$ in comparison to platinum complexes. ${ }^{83}$

Some reactive platinum complexes were appended by polyaromatic structures to improve the affinity towards DNA. By using the classical intercalator acridine connected to a platinum site $\mathbf{1 1 5}$ and the reference quadruplex $A_{3}\left(T_{2} A G_{3}\right)_{3}$ a binding preference A-N7 > G-N7 > A-N1 > A-N3 was observed, which is in fair contrast with cisplatin and hence demonstrate the non-innocence of the vectoring group. ${ }^{119}$ Because acridine intercalates easily into duplex DNA it was lately replaced by benz[c]acridine, which is more selective towards G4, in particular the antiparallel topology. ${ }^{120}$ The pyridodicarboxamide moieties was also reported for directing the bisiodoplatinum complex $\mathbf{1 1 6}$ (the iodide is an excellent leaving group) towards $G 4 .{ }^{121}$ Platination of the folded $A G_{3}\left(T_{2} A G_{3}\right)_{3}$ (Figure 11) occurs at both the adenine of the loops (A7, A13 and A19) and guanines ( $G 2, G 22)$. These sites are different from those of the reference complex lacking the pyridodicarboxamide group, showing that platination occurs after stacking of this moiety onto the $\mathrm{G} 4$, and confirms the non-innocence of the targeting moieties. 


\section{Bioconjugates}

The conjugation between a biomolecule and a ligand can be used for distinct purposes depending on the respective size of the two fragments. When large biological molecules (nucleic acids) are appended by a ligand, they are typically used for controlling the conformation or providing it with new functionalities. On the other hand when well-defined ligands are functionalized with small biological bricks (e.g. base, oligopeptides), they are generally used to modulate their properties or interact with the target.

\subsection{Control of the structuration}

An illustration of the first situation is the functionalization of short poly-G oligonucleotides by a terminal monodentate chelating moieties (imidazole or pyridine, schematized as 117) (Figure 12a). ${ }^{122,}$ ${ }^{123}$ Parallel tetramolecular quadruplexes form both in the absence and presence of copper, however a strong thermal stabilization of the structure is observed in the latter case, which is verified by a increase of the melting temperature by up to $51^{\circ} \mathrm{C}$ in the most favorable cases. Another noticeable consequence of metal ligation is a dramatic acceleration of G4 formation. The driving force for the reaction is of course metal chelation by the four pyridine or imidazole groups that affords 1:4 (M:L) complexes showing an in-plane four-coordinate copper center at the top of the parallel quadruplex.

Within the same context the consecutive thymines within the $G 4$ forming sequence $d\left(G_{4} T_{4} G_{4}\right)$ were replaced by the bidentate $2,2^{\prime}$-bipyridine (118), which is a fairly good chelator. ${ }^{124}$ This ligand adopts two distinct conformations whether the metal is present or not. In the absence of metal an antiparallel G4 forms, with the pyridines orientated in a trans fashion (Figure 11b). Upon addition of the metal the pyridine rings rotate in order to adopt the coordinating cis-configuration, affording complexes of 1:2 (M:L) stoichiometry. The movement is accompanied by a switch of the $\mathrm{G} 4$ to the parallel conformation. 
(a)

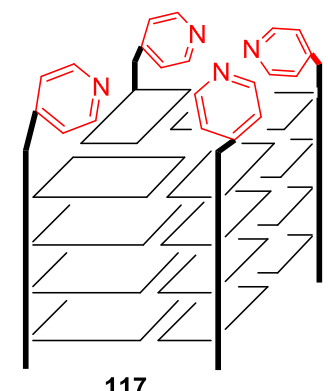

(c)

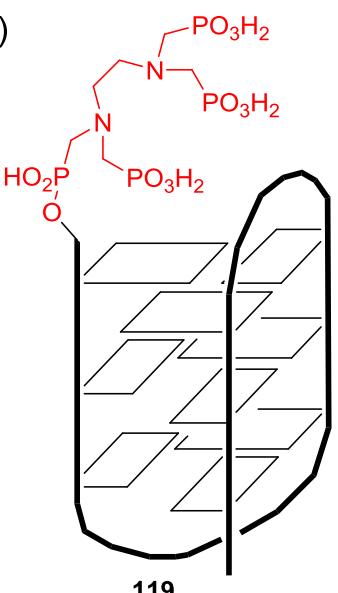

(b)

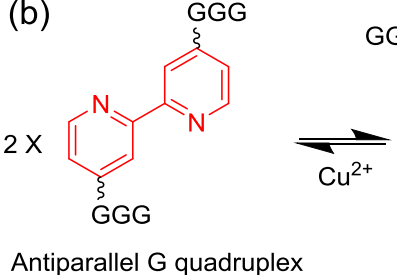

118

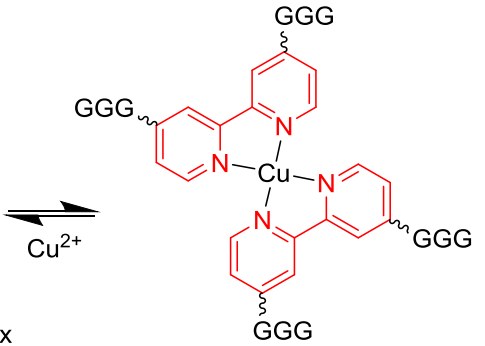

Parallel G quadruplex

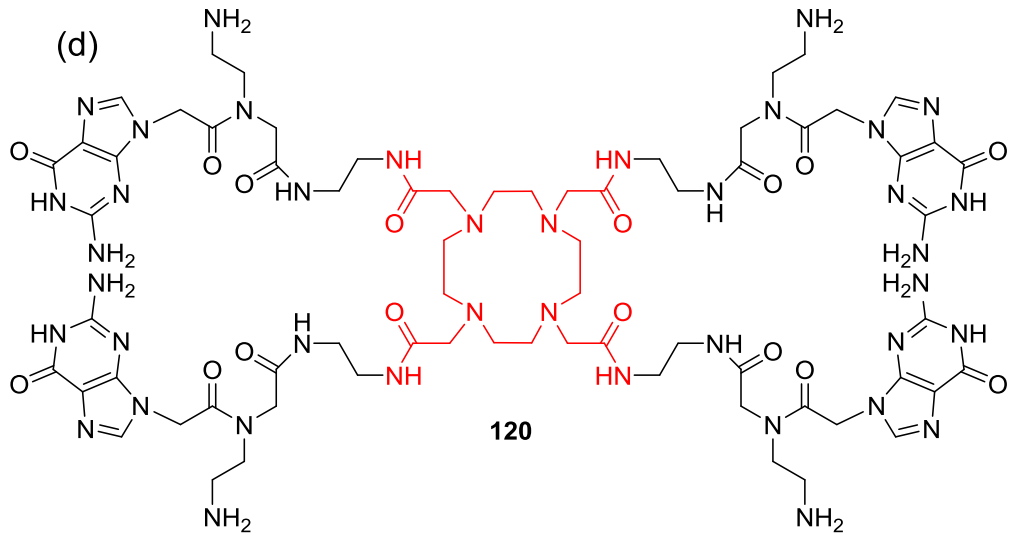

Figure 12. Bioconjugates DNA(base)/ligands. The chelating unit is shown in red.

\subsection{Incorporation of a reactive fragment}

With the aim of adding new functionalities a long oligonucleotide comprising three G-tracts was appended at the $5^{\prime}$ end by the ligand $N, N, N^{\prime}, N^{\prime}$ - ethylenediaminetetramethylenephosphonic acid (119, Figure 12c). ${ }^{125}$ Its polydentate nature implies that the stoichiometry of the formed complex is 1:1 (M:L). The investigated metal was Ce(IV), which provides nuclease properties to the complex. Hence, the functionalized oligonucleotide lacking a fourth strand binds strongly to single stranded human telomere DNA resulting in $\mathrm{G} 4$ formation. It is also capable of disrupting self-formed intramolecular G4 in the substrate DNA. The Ce(IV) complex subsequently promotes a sequencespecific strand break. The mechanism involves a nucleophilic attack of the pre-activated (deprotonated) coordinated water molecule, which is favored by the Lewis acidity of the metal ion.

In another approach the c-kit sequence (5'-AGGGAGGGCGCTGGGAGGAGGG-3') was functionalized on either position 10 or position 12 (apical loop segment) with a bipyridine moiety. ${ }^{126}$ The conjugate was used as catalyst for the asymmetric Michael reaction of a standard $\alpha, \beta$-unsaturated carbonyl and dimethyl malonate. Under G4 forming conditions the reaction proceeds with an enantiomeric excess of $52 \%$ in (+)-enantiomer when the bipyridine is attached in position 12, while it reaches $92 \%$ in (-)enantiomer when it is located in position 10. Further changes in the linker connecting the catalyst to DNA were found to affect the reaction outcome. Beyond biological considerations this is the first complex covalently bound to G4 for enantioselective catalysis (other examples of reactivity will be presented in a dedicated section for complexes not covalently linked to G4). 


\subsection{Strengthened interaction}

The last aspect of the bioconjugation is illustrated through the concept "who resembles likes", wherein biological bases were used for mediating the interaction of a ligand with G4 DNA. The DOTA platform, which is popular in the field of lanthanide coordination chemistry has been appended by four guanines (120, Figure 12d). ${ }^{127}$ While randomly organized in solution ("open" form) the ligand adopts a defined conformation in the presence of G4 targets, allowing for the top stacking of the guanines. Interestingly, the metal ion (terbium) does not participate in the structuration. Even worse it brings additional positive charges that are detrimental to the selectivity. Using a different approach octahedral $\mathrm{Ru}(\mathrm{II})$ complexes were synthesized from a bipyridine ligand functionalized with an octaarginine tract. ${ }^{128}$ This short oligopeptide is aimed at favoring internalization and nuclear delivery of the compound. Furthermore, its +8 charge drives strong electrostatic interactions with the $G 4$ phosphates, leading to micro or submicromolar $\mathrm{K}_{\mathrm{D}}$. 


\section{Reactivity with adducts formed between $\mathrm{G} 4$ and metal complexes}

The G4 can be used as a chiral inductor for a catalysis initiated at an exogenous metal center due to the elaboration of its structure into a chiral entity. The so-obtained DNAzymes were used to catalyze the enantioselective Diels-Alder reaction and sulfoxidation (Figure 13). While in most of the cases the structure of the metal complex - DNA adduct is unknown and the proposed affinity is weak, a substantial increase of the enantiomeric excess (ee) is systematically observed in the presence of G4. Further interesting examples of reactivity arise from the design of biophysical assays based on a peroxidase activity due to a bound heme activated by the G4, as well as Ru or Ir complexes capable of promoting photoreactions around G4 structures.

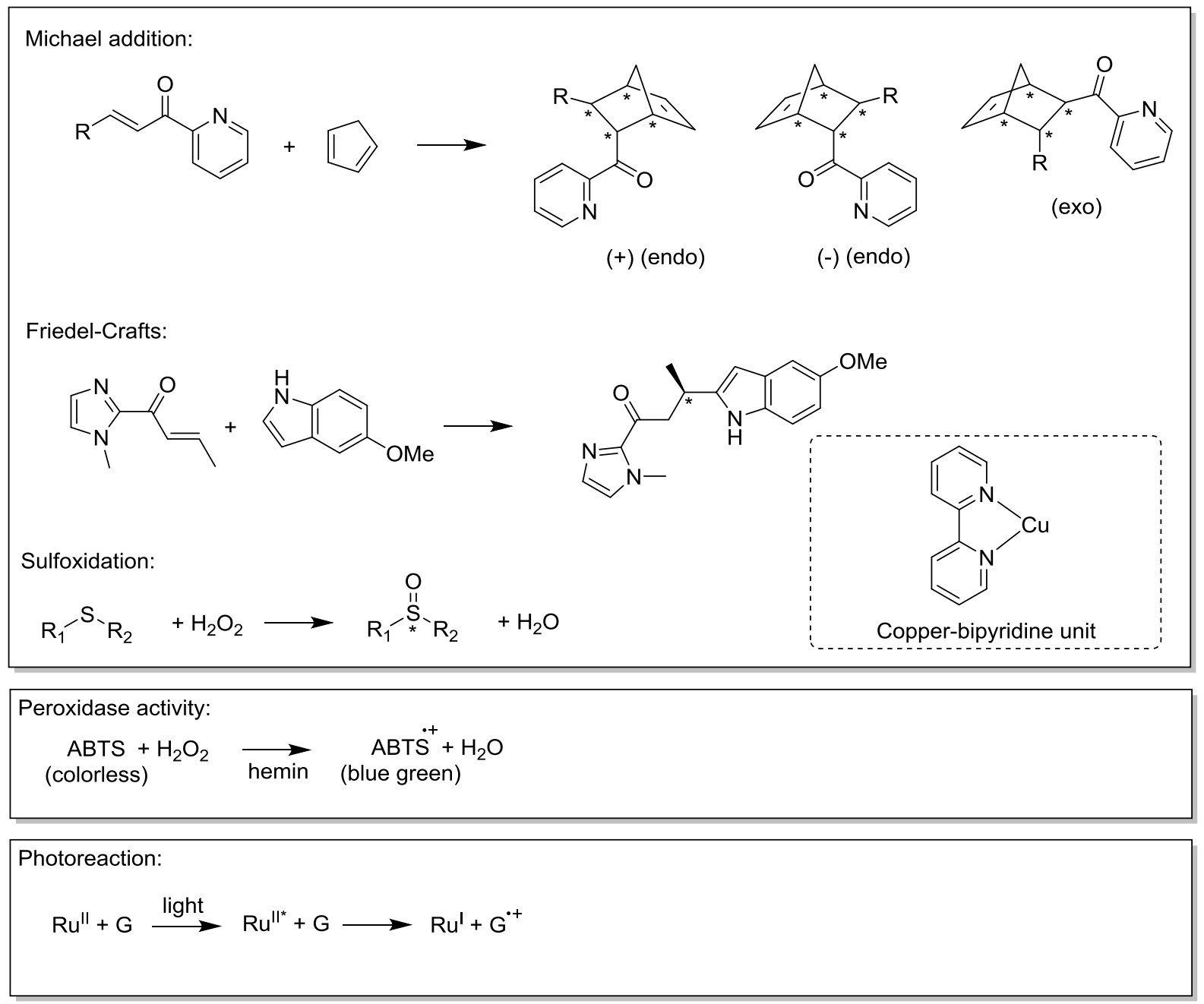

Figure 13. Representative reactions catalyzed by quadruplex/complex adducts

\subsection{Diels-Alder reaction}

Several sequences were investigated as scaffolds for the enantioselective Diels-Alder reaction between the aza-chalcone and cyclopentadiene (Figure 13). Defined copper bipyridine complexes were used in combination with two $\mathrm{G} 4 / \mathrm{K}^{+}$systems: The c-kit sequence (5'AGGGAGGGCGCTGGGAGGAGGG) that gives parallel folding and the hTelo sequence ( $5^{\prime}$ (AGGGTTA) ${ }_{3} \mathrm{GGG}$ ), which gives a mixture of topologies (antiparallel, parallel and hybrid forms), the 
anti-parallel structure being the main one. ${ }^{129}$ The reaction proved to be enantioselective and despite the fact that the ee is modest $(-46$ to $+48 \%)$ the relative chirality could be remarkably inverted depending upon the sequence and ligand. The related telomeric sequence $5^{\prime}-\mathrm{GGG}\left(\right.$ TTAGGG) ${ }_{3}-3^{\prime}$ was also investigated in combination with copper nitrate. ${ }^{130}$ An excellent diastereoselectivity was obtained (endo/exo of 98:2), as well as a good enantioselectivity ( $74 \%$ ee), which both depend on the concentration of structuring $\mathrm{Na}^{+}$in the medium. In this case loop mutations were employed to show that catalysis predominantly occurs in this region. An interesting effect of the structuring cation was illustrated through the reactivity of a telomeric variant $\left(5^{\prime}-(\text { GGGTTA })_{7}\right.$ GGG-3 $3^{\prime 29}$ in combination with the same nitrate copper salt: The endo product forms with ee $92 \%$ in the presence of $\mathrm{K}^{+}$, while in $\mathrm{NH}_{4}{ }^{+}$the ee is $-70 \%$. The reverse chiral induction on switching from $\mathrm{K}^{+}$to $\mathrm{NH}_{4}^{+}$illustrates the effect of subtle difference in chirality within the $\mathrm{G} 4$ on the enantioselectivity.

\subsection{Sulfoxidation reaction}

The human telomeric G4 DNA (5'-(GGGTTA) $\left.)_{3} G_{3}-3^{\prime}\right)$ was also examined for the enantioselective sulfoxidation reaction in combination with a series of 1:1 $\mathrm{Cu}(\mathrm{II})$ :complexes of 2,2'-bipyridine and phenanthroline. ${ }^{131}$ The medium was completed with $\mathrm{K}^{+}$, which induces the formation of various $\mathrm{G} 4$ topologies in solution. Notably when $\mathrm{K}^{+}$is either replaced by $\mathrm{Na}^{+}$or removed, the conversion drops dramatically, while racemic products are obtained, again demonstrating that the chiral induction is based on a $\mathrm{G} 4$ structuration. By using $\mathrm{H}_{2} \mathrm{O}_{2}$ as the oxidant, thioanisole as the substrate and copper bipyridine complexes as catalysts, an ee within the range $22-56 \%$ was obtained, with conversion up to $99 \%$. Based on a series of blanks (modified bases) it was proposed that both the upper G-tetrad and the loop region are involved in the enantioselective induction.

\subsection{Hemin and applications}

As discussed above the top quartet of telomeric G4 provides a preferential site for the stacking of porphyrins. In a seminal work in 1998 Sen et al. established that hemin, which is an iron porphyrin with peroxidase activity interacts tightly (submicromolar affinity) with G4. ${ }^{132}$ Most importantly they observed a dramatically enhanced peroxidase activity of the DNA-hemin complex in comparison to blanks with hemin and DNA lacking the propensity to bind hemes. Subsequent investigations point to effects of the G4 topology (higher activity with parallel folding) ${ }^{133}$ or the multimeric nature of the $\mathrm{G} 4{ }^{134}$ on the peroxidase activity. Modifications of the flanking sequences were also proposed to enhance the peroxidase activity ${ }^{135}$, as well the addition of exogenous agents. ${ }^{136}$ The fact that the peroxidase activity could be easily monitored by a colorimetric test employing ABTS as substrate or luminol with chemiluminescence detection paved for way for the development of biophysical assays. This has led to tests for the detection of various analytes including cations, nucleotides and even cancer cells. Major assays designed with hemin within the frame of G4 homeostasis are dedicated to the optical monitoring of the activity of telomerase. ${ }^{137-139}$

\subsection{Photochemistry}

The ruthenium and iridium metal ions exhibit peculiar photophysical and further photochemical properties when combined with appropriate ligands. Heteroleptic complexes of $\operatorname{Ru}(\mathrm{II})$ and $\operatorname{Ir}(\mathrm{III})$ were prepared, both incorporating the 2-(4-chlorophenyl)-1H-imidazo[4,5-f] $[1,10]$ phenanthroline ligand for targeting DNA. The co-ligand, which is the photo-induced electron transfer (PET) inducer was 1,4,5,8-tetraazaphenanthrene for Ru(II) (92) or 1-methyl-[2,2'-bipyridin]-1-ium for $\operatorname{Ir}(\mathrm{III})$ (100). Both complexes interact tightly with $\mathrm{G} 4$ ( $\mathrm{K}_{\mathrm{D}}$ within the micromolar range) and demonstrate a photo- 
induced electron transfer from the guanines to the excited state of the metal. ${ }^{102,}{ }^{106}$ For the $\operatorname{Ir}(I I I)$ complex the 8-oxo-dG lesions were evidenced in the hTelo sequence $\left({ }^{5^{\prime}}\right.$ TAGGG(TTAGGG) ${ }_{3}{ }^{3}$ ) upon irradiation, confirming the photoreaction with guanines but no selectivity of this photo-damage formation was observed for G4 versus duplex DNA. This is one of the first examples of $\operatorname{Ir}(I I I)$ complexes that can interact with G4 DNA and trigger electron transfer with guanine under light irradiation. Furthermore, photo-toxicity investigations were conducted with the ruthenium complex on cell cultures, revealing a dramatic decrease in survival upon irradiation. This toxicity was inferred to a photoreaction promoted by the internalized ruthenium complex that damages DNA.

\subsection{Oxidative G4 cleavage}

The last aspect of reactivity parallels the previous one since the $\mathrm{G} 4$ is the substrate of the reaction. Hence a perylenediimine moiety (PIPER), which is a recognized organic G4 binder, was functionalized by two EDTA units, each chelated to Fe(II). ${ }^{140}$ The complex shows high affinity for quadruplexes and, in the presence of a reducing agent a Fenton-like reactivity is observed, whereby generation of hydroxyl radicals damages specific regions of the G4. A high-valent Mn oxo species was generated from 30 in the presence of the oxidant $\mathrm{KHSO}_{5}{ }^{141}$ The activated complex interacts with hTelo and induces oxidative damages to the guanines located in the top tetrad. Additional damages were observed on the deoxyribose unit of the thymidine located in the nearby region (single-stranded loop).

\section{Biological applications of inorganic $\mathrm{G} 4$ binders}

Amongst the various potential applications of G4 binders two have been the focus on significant interest in the past decade: the identification and the stabilization of these peculiar DNA topologies in the genome. The development of tools allowing an easy detection of G4 is highly desirable for gaining insight into their properties and recurrence in the genome, while their stabilization (which may be associated to detection) will induce a cellular response and hence may be exploited for therapeutic purposes, in particular the development of new anti-cancer drugs. We will not discuss in this section biological tests (e.g. TRAP and TRAP G4) aimed at quantifying telomerase inhibition in vitro nor fluorescence measurements in vitro, but focus on in cellulo applications (Figure 14).

\subsection{Fluorescent probes for imaging}

Fluorescence microscopy is the most straightforward approach for detecting $\mathrm{G} 4$ in biological media and confirming that their cellular target is effectively DNA. This implies the design of fluorescent G4 binders. ${ }^{142}$ The platinum ion is a metal of choice for such investigations since it fluoresces when bound to DNA, in contrast with free complexes that are non-emissive in solution due to non-radiative deactivation of the excited state by interactions with the solvent. Hence the widely represented nickel salphen family could be made fluorescent at low synthetic cost by substituting $\mathrm{Ni}$ (II) by $\mathrm{Pt}$ (II) $(5,9,11,121)$ since both show the same geometrical preference. Octahedral ruthenium polypyridyl complexes also show interesting luminescence properties when the photoreactivity does not prevail (see section 9). ${ }^{102}$ In both cases an increase in luminescence is observed upon binding to G4, making these complexes powerful switch-on probes. By confocal microscopy it could be established that both the salophen platinum complexes $\mathbf{9 - 1 0}$ and $\mathbf{1 2 1 ^ { 5 6 }}$ and ruthenium polypyridyl complexes $\mathbf{1 2 2}{ }^{143}$ enter the cells and, most importantly, localize in the nucleus. It was also suggested that the latter is a 
luminescent marker for quadruplex DNA in cellulo. An alternative strategy is based on the exploitation of the intrinsic ligand fluorescence when chelated to a $d^{10}$ metal ion $(\mathrm{Zn}(\mathrm{II})){ }^{78,79}$ or the functionalization of the ligand by fluorescent groups when it is not naturally luminescent. Interesting examples are the phtalocyanin $\mathbf{4 5}$ and the fluorescein appended salophen complexes 23-24, which also localizes in the nucleus. ${ }^{62}$ Beyond optical monitoring of G4 in cellulo, it should be mentioned that sensitive colorimetric tests of the telomerase activity in various cell extracts were designed. ${ }^{139}$ They are mainly based on the G4-hemin DNAzyme, whose principle of the functioning is discussed in section 9 (Fig. 12).
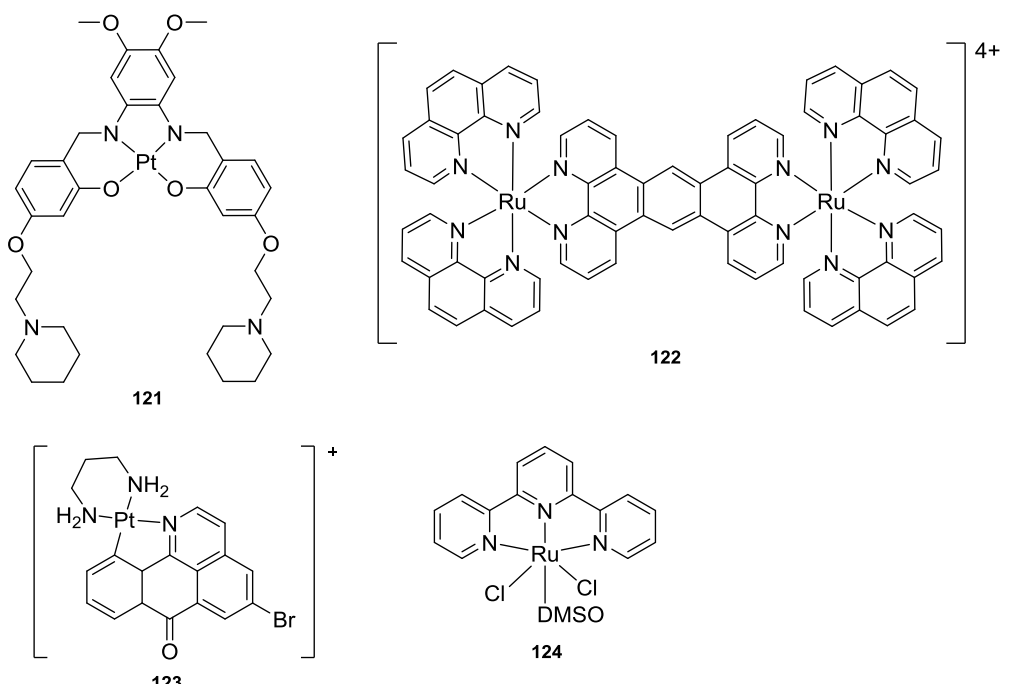

Figure 14. Representative complexes for either imaging or inducing a down-regulation of specific genes

\subsection{Biological activity}

The targets of the cell-permeable G4 binders are ideally the telomeres and the promoter region of certain oncogenes. Strong and specific binding is thus expected to perturb either the biological clock or gene expression. The cytotoxicity of the complexes is classically evaluated using MTT assays, but direct correlations between any toxicity and binding to $\mathrm{G} 4$ in cellulo remains challenging to demonstrate. Hence only few complexes were shown to induce a cellular response imputable to binding to G4: A down-regulation of the gene expression (protooncogen c-myc) was for example observed in cellulo for distinct classes of $\mathrm{Pt}(\mathrm{II})$ complexes, including salophen $\mathbf{1 2 1},{ }^{144}$ tridentates $\mathbf{6 0}$ $\mathbf{6 1}$ and $\mathbf{6 4},{ }^{85} 5$-bromo-5oxoisoaporphin $123,{ }^{145}$ as well as $\mathrm{Ru}(\mathrm{II})$ complexes of terpyridines such as $\mathbf{1 2 4}$ ${ }^{146}$. On the other hand both the pyridodicarboxamide appended $\mathrm{Pt}(\mathrm{II})$ complex $116^{121}$ and the supramolecular cylinder $109{ }^{113}$ were shown to displace telomere associated proteins, which protect the telomere from instability and damages. The telomere uncapping by $\mathbf{1 0 9}$ is followed by telomeric DNA damage and further apoptosis, and was demonstrated to eliminate breast cancer stem cells in vivo. These important results disclose a rational between the observed in vitro binding ability of G4 binders and the observed cellular response. 


\section{Summary and outlook}

The G4 DNA is becoming a promising target for treating cancer. The binding properties of an exponential number of metallic complexes for this canonical form of DNA have been investigated during the past two decades. These efforts lead to the identification of key determinants for a high affinity and selectivity for quadruplex vs. duplexes. Having these data in hand new directions are now being explored, including further selectivity, reactivity, sensng, in cellulo applications and hopefully therapy.

\section{References}

1. T. Tian, Y.-Q. Chen, S.-R. Wang and X. Zhou, Chem, 2018, 4, 1314-1344.

2. A. I. Karsisiotis, C. O'Kane and M. Webba da Silva, Methods, 2013, 64, 28-35.

3. J. L. Huppert and S. Balasubramanian, Nucleic Acids Res., 2007, 35, 406-413.

4. S. Balasubramanian, L. H. Hurley and S. Neidle, Nat. Rev. Drug. Discov., 2011, 10, 261-275.

5. M. K. Islam, P. J. Jackson, K. M. Rahman and D. E. Thurston, Future Med. Chem., 2016, 8, 1259-1290.

6. M. Y. Kim, H. Vankayalapati, S. Kazuo, K. Wierzba and L. H. Hurley, J. Am. Chem. Soc., 2002, 124, 2098-2099.

7. N. H. Campbell, G. N. Parkinson, A. P. Reszka and S. Neidle, J. Am. Chem. Soc., 2008, 130, 6722-+.

8. S. N. Georgiades, N. H. Abd Karim, K. Suntharalingam and R. Vilar, Angew. Chem. Int. Ed., 2010, 49, 4020-4034.

9. Q. Cao, Y. Li, E. Freisinger, P. Z. Qin, R. K. O. Sigel and Z.-W. Mao, Inorg. Chem. Front., 2017, 4, 10-32.

10. E. Ruggiero and S. N. Richter, Nucleic Acids Res., 2018, 46, 3270-3283.

11. R. Vilar, Met. lons Life Sci., 2018, 18, 325-349.

12. S. Asamitsu, T. Bando and H. Sugiyama, Chem. Eur. J., 2019, 25, 417-430.

13. A. Varizhuk, D. Ischenko, V. Tsvetkov, R. Novikov, N. Kulemin, D. Kaluzhny, M. Vlasenok, V. Naumov, I. Smirnov and G. Pozmogova, Biochimie, 2017, 135, 54-62.

14. T. I. Gaynutdinov, R. D. Neumann and I. G. Panyutin, Nucleic Acids Res., 2008, 36, 4079-4087.

15. J. X. Dai, M. Carver and D. Z. Yang, Biochimie, 2008, 90, 1172-1183.

16. A. Randazzo, G. P. Spada and M. W. da Silva, Top. Curr. Chem., 2013, 330, 67-86.

17. A. M. Zahler, J. R. Williamson, T. R. Cech and D. M. Prescott, Nature, 1991, 350, 718-720.

18. G. Biffi, D. Tannahill, J. McCafferty and S. Balasubramanian, Nat. chem., 2013, 5, 182-186.

19. A. K. Todd, M. Johnston and S. Neidle, Nucleic Acids Res., 2005, 33, 2901-2907.

20. J. L. Huppert and S. Balasubramanian, Nucleic Acids Res., 2005, 33, 2908-2916.

21. A. Bedrat, L. Lacroix and J. L. Mergny, Nucleic Acids Res., 2016, 44, 1746-1759.

22. V. S. Chambers, G. Marsico, J. M. Boutell, M. Di Antonio, G. P. Smith and S. Balasubramanian, Nat. Biotechnol., 2015, 33, 877-881.

23. R. Hansel-Hertsch, D. Beraldi, S. V. Lensing, G. Marsico, K. Zyner, A. Parry, M. Di Antonio, J. Pike, H. Kimura, M. Narita, D. Tannahill and S. Balasubramanian, Nat. Genet., 2016, 48, 12671272.

24. E. Lavezzo, M. Berselli, I. Frasson, R. Perrone, G. Palu, A. R. Brazzale, S. N. Richter and S. Toppo, PLoS Comput. Biol., 2018, 14, e1006675.

25. A. L. Moye, K. C. Porter, S. B. Cohen, T. Phan, K. G. Zyner, N. Sasaki, G. O. Lovrecz, J. L. Beck and T. M. Bryan, Nat. Commun., 2015, 6, 7643.

26. M. Sauer and K. Paeschke, Biochem. Soc. Trans., 2017, 45, 1173-1182. 
27. Q. He, P. Zeng, J. H. Tan, T. M. Ou, L. Q. Gu, Z. S. Huang and D. Li, Biochim. Biophys. Acta, 2014, 1840, 2222-2233.

28. S. Ray, J. N. Bandaria, M. H. Qureshi, A. Yildiz and H. Balci, Proc. Natl. Acad. Sci. USA, 2014, 111, 2990-2995.

29. D. Rhodes and H. J. Lipps, Nucleic Acids Res., 2015, 43, 8627-8637.

30. V. Gonzalez, K. X. Guo, L. Hurley and D. Sun, J. Biol. Chem., 2009, 284, 23622-23635.

31. N. Kim, Curr. Med. Chem., 2019, 26, 2898-2917.

32. A. Bugaut and S. Balasubramanian, Nucleic Acids Res., 2012, 40, 4727-4741.

33. S. Kumari, A. Bugaut and S. Balasubramanian, Biochemistry, 2008, 47, 12664-12669.

34. C. Wang, L. Zhao and S. Lu, Int. J. Biol. Sci., 2015, 11, 316-323.

35. R. Simone, P. Fratta, S. Neidle, G. N. Parkinson and A. M. Isaacs, FEBS letters, 2015, 589, 1653-1668.

36. M. Metifiot, S. Amrane, S. Litvak and M. L. Andreola, Nucleic Acids Res, 2014, 42, $12352-$ 12366.

37. B. De Nicola, C. J. Lech, B. Heddi, S. Regmi, I. Frasson, R. Perrone, S. N. Richter and A. T. Phan, Nucleic Acids Res., 2016, 44, 6442-6451.

38. D. Y. Sun, B. Thompson, B. E. Cathers, M. Salazar, S. M. Kerwin, J. O. Trent, T. C. Jenkins, S. Neidle and L. H. Hurley, J. Med. Chem., 1997, 40, 2113-2116.

39. A. R. Duarte, E. Cadoni, A. S. Ressurreicao, R. Moreira and A. Paulo, ChemMedChem, 2018, 13, 869-893.

40. D. Monchaud and M. P. Teulade-Fichou, Org. Biomol. Chem., 2008, 6, 627-636.

41. A. De Cian, E. DeLemos, J. L. Mergny, M. P. Teulade-Fichou and D. Monchaud, J. Am. Chem. Soc., 2007, 129, 1856-1857.

42. S. Muller, D. A. Sanders, M. Di Antonio, S. Matsis, J. F. Riou, R. Rodriguez and S. Balasubramanian, Org. Biomol. Chem., 2012, 10, 6537-6546.

43. A. M. Burger, F. P. Dai, C. M. Schultes, A. P. Reszka, M. J. Moore, J. A. Double and S. Neidle, Cancer Res., 2005, 65, 1489-1496.

44. T. Tauchi, K. Shin-ya, G. Sashida, M. Sumi, A. Nakajima, T. Shimamoto, J. H. Ohyashiki and K. Ohyashiki, Oncogene, 2003, 22, 5338-5347.

45. T. A. Brooks and L. H. Hurley, Genes \& cancer, 2010, 1, 641-649.

46. R. Perrone, F. Doria, E. Butovskaya, I. Frasson, S. Botti, M. Scalabrin, S. Lago, V. Grande, M. Nadai, M. Freccero and S. N. Richter, J. Med. Chem., 2015, 58, 9639-9652.

47. R. Perrone, E. Butovskaya, D. Daelemans, G. Palu, C. Pannecouque and S. N. Richter, J. Antimicrob. Chemother., 2014, 69, 3248-3258.

48. R. Rocca, C. Talarico, F. Moraca, G. Costa, I. Romeo, F. Ortuso, S. Alcaro and A. Artese, Chem. Biol. Drug Des., 2017, 90, 919-925.

49. S. K. Wang, Y. Wu, X. Q. Wang, G. T. Kuang, Q. Zhang, S. L. Lin, H. Y. Liu, J. H. Tan, Z. S. Huang and T. M. Ou, J. Med. Chem., 2017, 60, 5306-5319.

50. N. M. Smith, S. Amrane, F. Rosu, V. Gabelica and J.-L. Mergny, Chem. Commun., 2012, 48, 11464-11466.

51. M. Wang, Z. Mao, T.-S. Kang, C.-Y. Wong, J.-L. Mergny, C.-H. Leung and D.-L. Ma, Chemical Science, 2016, 7, 2516-2523.

52. C. Wei, G. Jia, J. Zhou, G. Han and C. Li, PCCP, 2009, 11, 4025-4032.

53. A. Arola-Arnal, J. Benet-Buchholz, S. Neidle and R. Vilar, Inorg. Chem., 2008, 47, 1191011919.

54. L. Lecarme, E. Prado, A. De Rache, M.-L. Nicolau-Travers, R. Bonnet, A. v. D. Heyden, C. Philouze, D. Gomez, J.-L. Mergny, H. Jamet, E. Defrancq, O. Jarjayes and F. Thomas, Inorg. Chem., 2014, 53, 12519-12531.

55. K. J. Davis, C. Richardson, J. L. Beck, B. M. Knowles, A. Guédin, J.-L. Mergny, A. C. Willis and S. F. Ralph, Dalton Trans., 2015, 44, 3136-3150.

56. N. H. Abd Karim, O. Mendoza, A. Shivalingam, A. J. Thompson, S. Ghosh, M. K. Kuimova and R. Vilar, RSC Advances, 2014, 4, 3355-3363. 
57. S. S. Mandal, U. Varshney and S. Bhattacharya, Bioconjugate Chem., 1997, 8, 798-812.

58. J. G. Muller, L. A. Kayser, S. J. Paikoff, V. Duarte, N. Tang, R. J. Perez, S. E. Rokita and C. J. Burrows, Coord. Chem. Rev., 1999, 185-186, 761-774.

59. L. Lecarme, E. Prado, A. De Rache, M.-L. Nicolau-Travers, G. Gellon, J. Dejeu, T. Lavergne, H. Jamet, D. Gomez, J.-L. Mergny, E. Defrancq, O. Jarjayes and F. Thomas, ChemMedChem, 2016, 11, 1133-1136.

60. A. Terenzi, D. Lötsch, S. van Schoonhoven, A. Roller, C. R. Kowol, W. Berger, B. K. Keppler and G. Barone, Dalton Trans., 2016, 45, 7758-7767.

61. N. H. Campbell, N. H. A. Karim, G. N. Parkinson, M. Gunaratnam, V. Petrucci, A. K. Todd, R. Vilar and S. Neidle, J. Med. Chem., 2012, 55, 209-222.

62. A. Ali, M. Kamra, S. Roy, K. Muniyappa and S. Bhattacharya, Bioconjugate Chem., 2017, 28, 341-352.

63. S. Bandeira, J. Gonzalez-Garcia, E. Pensa, T. Albrecht and R. Vilar, Angew. Chem. Int. Ed., 2018, 57, 310-313.

64. C. L. Ruehl, A. H. M. Lim, T. Kench, D. J. Mann and R. Vilar, Chem. Eur. J., 2019, 25, 9691-9700.

65. R. T. Wheelhouse, D. Sun, H. Han, F. X. Han and L. H. Hurley, J. Am. Chem. Soc., 1998, 120, 3261-3262.

66. D.-F. Shi, R. T. Wheelhouse, D. Sun and L. H. Hurley, J. Med. Chem., 2001, 44, 4509-4523.

67. E. Izbicka, R. T. Wheelhouse, E. Raymond, K. K. Davidson, R. A. Lawrence, D. Sun, B. E. Windle, L. H. Hurley and D. D. Von Hoff, Cancer Research, 1999, 59, 639-644.

68. S. Y. Rha, E. Izbicka, R. Lawrence, K. Davidson, D. Sun, M. P. Moyer, G. D. Roodman, L. Hurley and D. Von Hoff, Clin. Cancer Res., 2000, 6, 987-993.

69. I. M. Dixon, F. Lopez, J.-P. Estève, A. M. Tejera, M. A. Blasco, G. Pratviel and B. Meunier, ChemBioChem, 2005, 6, 123-132.

70. A. Maraval, S. Franco, C. Vialas, G. Pratviel, M. A. Blasco and B. Meunier, Org. Biomol. Chem., 2003, 1, 921-927.

71. L. R. Keating and V. A. Szalai, Biochemistry, 2004, 43, 15891-15900.

72. A. J. Bhattacharjee, K. Ahluwalia, S. Taylor, O. Jin, J. M. Nicoludis, R. Buscaglia, J. Brad Chaires, D. J. P. Kornfilt, D. G. S. Marquardt and L. A. Yatsunyk, Biochimie, 2011, 93, 1297-1309.

73. I. M. Dixon, F. Lopez, A. M. Tejera, J.-P. Estève, M. A. Blasco, G. Pratviel and B. Meunier, J. Am. Chem. Soc., 2007, 129, 1502-1503.

74. C. Romera, O. Bombarde, R. Bonnet, D. Gomez, P. Dumy, P. Calsou, J.-F. Gwan, J.-H. Lin, E. Defrancq and G. Pratviel, Biochimie, 2011, 93, 1310-1317.

75. A. Pipier, A. De Rache, C. Modeste, S. Amrane, E. Mothes-Martin, J.-L. Stigliani, P. Calsou, J.-L. Mergny, G. Pratviel and D. Gomez, Dalton Trans., 2019, 48, 6091-6099.

76. L. Ren, A. Zhang, J. Huang, P. Wang, X. Weng, L. Zhang, F. Liang, Z. Tan and X. Zhou, ChemBioChem, 2007, 8, 775-780.

77. L. Zhang, J. Huang, L. Ren, M. Bai, L. Wu, B. Zhai and X. Zhou, Bioorg Med Chem, 2008, 16, 303-312.

78. J. Alzeer, B. R. Vummidi, P. J. C. Roth and N. W. Luedtke, Angew. Chem. Int. Ed., 2009, 48, 9362-9365.

79. A. Membrino, M. Paramasivam, S. Cogoi, J. Alzeer, N. W. Luedtke and L. E. Xodo, Chem. Commun., 2010, 46, 625-627.

80. Z. Gershman, I. Goldberg and Z. Gross, Angew. Chem. Int. Ed., 2007, 46, 4320-4324.

81. B. Fu, D. Zhang, X. Weng, M. Zhang, H. Ma, Y. Ma and X. Zhou, Chem. Eur. J., 2008, 14, 94319441.

82. H. Bertrand, D. Monchaud, A. De Cian, R. Guillot, J.-L. Mergny and M.-P. Teulade-Fichou, Org. Biomol. Chem., 2007, 5, 2555-2559.

83. E. Largy, F. Hamon, F. Rosu, V. Gabelica, E. De Pauw, A. Guédin, J.-L. Mergny and M.-P. Teulade-Fichou, Chem. Eur. J., 2011, 17, 13274-13283.

84. K. Suntharalingam, A. J. P. White and R. Vilar, Inorg. Chem., 2009, 48, 9427-9435.

85. P. Wang, C.-H. Leung, D.-L. Ma, S.-C. Yan and C.-M. Che, Chem. Eur. J., 2010, 16, 6900-6911. 
86. Z. Ou, Z. Feng, G. Liu, Y. Chen, Y. Gao, Y. Li and X. Wang, Chem. Lett., 2015, 44, 425-427.

87. J.-T. Wang, X.-H. Zheng, Q. Xia, Z.-W. Mao, L.-N. Ji and K. Wang, Dalton Trans., 2010, 39, 7214-7216.

88. J. E. Reed, S. Neidle and R. Vilar, Chem. Commun., 2007, DOI: 10.1039/B709898G, 4366-4368.

89. J. E. Reed, A. J. P. White, S. Neidle and R. Vilar, Dalton Trans., 2009, DOI: 10.1039/B820086F, 2558-2568.

90. S. Bianco, C. Musetti, A. Waldeck, S. Sparapani, J. D. Seitz, A. P. Krapcho, M. Palumbo and C. Sissi, Dalton Trans., 2010, 39, 5833-5841.

91. K. E. Erkkila, D. T. Odom and J. K. Barton, Chem. Rev., 1999, 99, 2777-2796.

92. D.-L. Ma, C.-M. Che and S.-C. Yan, J. Am. Chem. Soc., 2009, 131, 1835-1846.

93. R. Kieltyka, P. Englebienne, J. Fakhoury, C. Autexier, N. Moitessier and H. F. Sleiman, J. Am. Chem. Soc., 2008, 130, 10040-10041.

94. K. J. Castor, J. Mancini, J. Fakhoury, N. Weill, R. Kieltyka, P. Englebienne, N. Avakyan, A. Mittermaier, C. Autexier, N. Moitessier and H. F. Sleiman, ChemMedChem, 2012, 7, 85-94.

95. S. Shi, X. Geng, J. Zhao, T. Yao, C. Wang, D. Yang, L. Zheng and L. Ji, Biochimie, 2010, 92, 370377.

96. G. Liao, X. Chen, J. Wu, C. Qian, H. Wang, L. Ji and H. Chao, Dalton Trans., 2014, 43, 78117819.

97. Z. Zhang, Q. Wu, X.-H. Wu, F.-Y. Sun, L.-M. Chen, J.-C. Chen, S.-L. Yang and W.-J. Mei, Eur. J. Med. Chem., 2014, 80, 316-324.

98. L. He, X. Chen, Z. Meng, J. Wang, K. Tian, T. Li and F. Shao, Chem. Commun., 2016, 52, 80958098.

99. D. Saadallah, M. Bellakhal, S. Amor, J.-F. Lefebvre, M. Chavarot-Kerlidou, I. Baussanne, C. Moucheron, M. Demeunynck and D. Monchaud, Chem. Eur. J., 2017, 23, 4967-4972.

100. X. Chen, J.-H. Wu, Y.-W. Lai, R. Zhao, H. Chao and L.-N. Ji, Dalton Trans., 2013, 42, 4386-4397.

101. D. Sun, Y. Liu, D. Liu, R. Zhang, X. Yang and J. Liu, Chem. Eur. J., 2012, 18, 4285-4295.

102. J. Weynand, A. Diman, M. Abraham, L. Marcélis, H. Jamet, A. Decottignies, J. Dejeu, E. Defrancq and B. Elias, Chem. Eur. J., 2018, 24, 19216-19227.

103. S. Lin, L. Lu, T.-S. Kang, J.-L. Mergny, C.-H. Leung and D.-L. Ma, Anal. Chem., 2016, 88, 1029010295.

104. L. Lu, M. Wang, Z. Mao, T.-S. Kang, X.-P. Chen, J.-J. Lu, C.-H. Leung and D.-L. Ma, Scientific Reports, 2016, 6, 22458.

105. K. J. Castor, K. L. Metera, U. M. Tefashe, C. J. Serpell, J. Mauzeroll and H. F. Sleiman, Inorg. Chem., 2015, 54, 6958-6967.

106. J. Weynand, H. Bonnet, F. Loiseau, J.-L. Ravanat, J. Dejeu, E. Defrancq and B. Elias, Chem. Eur. J., 2019, 25, 12730-12739.

107. A. Garci, K. J. Castor, J. Fakhoury, J.-L. Do, J. Di Trani, P. Chidchob, R. S. Stein, A. K. Mittermaier, T. Friščić and H. Sleiman, J. Am. Chem. Soc., 2017, 139, 16913-16922.

108. X.-H. Zheng, Y.-F. Zhong, C.-P. Tan, L.-N. Ji and Z.-W. Mao, Dalton Trans., 2012, 41, 1180711812.

109. X.-H. Zheng, H.-Y. Chen, M.-L. Tong, L.-N. Ji and Z.-W. Mao, Chem. Commun., 2012, 48, 76077609.

110. O. Domarco, D. Lötsch, J. Schreiber, C. Dinhof, S. Van Schoonhoven, M. D. García, C. Peinador, B. K. Keppler, W. Berger and A. Terenzi, Dalton Trans., 2017, 46, 329-332.

111. S. Ghosh, O. Mendoza, L. Cubo, F. Rosu, V. Gabelica, A. J. P. White and R. Vilar, Chem. Eur. J., 2014, 20, 4772-4779.

112. H. Yu, X. Wang, M. Fu, J. Ren and X. Qu, Nucleic Acids Res., 2008, 36, 5695-5703.

113. H. Qin, C. Zhao, Y. Sun, J. Ren and X. Qu, J. Am. Chem. Soc., 2017, 139, 16201-16209.

114. S.-F. Xi, L.-Y. Bao, Z.-L. Xu, Y.-X. Wang, Z.-D. Ding and Z.-G. Gu, Eur. J. Inorg. Chem., 2017, 2017, 3533-3541.

115. S. Redon, S. Bombard, M. A. Elizondo-Riojas and J. C. Chottard, Biochemistry, 2001, 40, 84638470 . 
116. S. Redon, S. Bombard, M. A. Elizondo-Riojas and J. C. Chottard, Nucleic Acids Res., 2003, 31, 1605-1613.

117. I. Ourliac-Garnier, M.-A. Elizondo-Riojas, S. Redon, N. P. Farrell and S. Bombard, Biochemistry, 2005, 44, 10620-10634.

118. H. Bertrand, S. Bombard, D. Monchaud, E. Talbot, A. Guédin, J.-L. Mergny, R. Grünert, P. J. Bednarski and M.-P. Teulade-Fichou, Org. Biomol. Chem., 2009, 7, 2864-2871.

119. L. Rao and U. Bierbach, J. Am. Chem. Soc., 2007, 129, 15764-15765.

120. A. J. Pickard, F. Liu, T. F. Bartenstein, L. G. Haines, K. E. Levine, G. L. Kucera and U. Bierbach, Chem. Eur. J., 2014, 20, 16174-16187.

121. J.-F. Betzer, F. Nuter, M. Chtchigrovsky, F. Hamon, G. Kellermann, S. Ali, M.-A. Calméjane, S. Roque, J. Poupon, T. Cresteil, M.-P. Teulade-Fichou, A. Marinetti and S. Bombard, Bioconjugate Chem., 2016, 27, 1456-1470.

122. D. M. Engelhard, R. Pievo and G. H. Clever, Angew. Chem. Int. Ed., 2013, 52, 12843-12847.

123. D. M. Engelhard, L. M. Stratmann and G. H. Clever, Chem. Eur. J., 2018, 24, 2117-2125.

124. D. Miyoshi, H. Karimata, Z.-M. Wang, K. Koumoto and N. Sugimoto, J. Am. Chem. Soc., 2007, 129, 5919-5925.

125. Y. Xu, Y. Suzuki, T. Lönnberg and M. Komiyama, J. Am. Chem. Soc., 2009, 131, 2871-2874.

126. S. Dey and A. Jäschke, Angew. Chem. Int. Ed., 2015, 54, 11279-11282.

127. R. Haudecoeur, L. Stefan, F. Denat and D. Monchaud, J. Am. Chem. Soc., 2013, 135, 550-553.

128. D. Bouzada, I. Salvadó, G. Barka, G. Rama, J. Martínez-Costas, R. Lorca, Á. Somoza, M. MelleFranco, M. E. Vázquez and M. Vázquez López, Chem. Commun., 2018, 54, 658-661.

129. S. Roe, D. J. Ritson, T. Garner, M. Searle and J. E. Moses, Chem. Commun., 2010, 46, 43094311.

130. C. Wang, G. Jia, J. Zhou, Y. Li, Y. Liu, S. Lu and C. Li, Angew. Chem. Int. Ed., 2012, 51, 93529355.

131. M. Cheng, Y. Li, J. Zhou, G. Jia, S.-M. Lu, Y. Yang and C. Li, Chem. Commun., 2016, 52, 96449647.

132. P. Travascio, Y. Li and D. Sen, Chem. Biol., 1998, 5, 505-517.

133. D.-M. Kong, W. Yang, J. Wu, C.-X. Li and H.-X. Shen, Analyst, 2010, 135, 321-326.

134. L. Stefan, F. Denat and D. Monchaud, J. Am. Chem. Soc., 2011, 133, 20405-20415.

135. T. Chang, H. Gong, P. Ding, X. Liu, W. Li, T. Bing, Z. Cao and D. Shangguan, Chem. Eur. J., 2016, 22, 4015-4021.

136. C. Qi, N. Zhang, J. Yan, X. Liu, T. Bing, H. Mei and D. Shangguan, RSC Advances, 2014, 4, 14411448.

137. Y. Xiao, V. Pavlov, T. Niazov, A. Dishon, M. Kotler and I. Willner, J. Am. Chem. Soc., 2004, 126, 7430-7431.

138. R. Freeman, E. Sharon, C. Teller, A. Henning, Y. Tzfati and I. Willner, ChemBioChem, 2010, 11, 2362-2367.

139. Y. Wang, L. Yang, Y. Wang, W. Liu, B. Li and Y. Jin, Analyst, 2019, 144, 5959-5964.

140. W. Tuntiwechapikul and M. Salazar, Biochemistry, 2001, 40, 13652-13658.

141. C. Vialas, G. Pratviel and B. Meunier, Biochemistry, 2000, 39, 9514-9522.

142. B. R. Vummidi, J. Alzeer and N. W. Luedtke, ChemBioChem, 2013, 14, 540-558.

143. M. R. Gill, J. Garcia-Lara, S. J. Foster, C. Smythe, G. Battaglia and J. A. Thomas, Nat. Chem., 2009, 1, 662-667.

144. P. Wu, D.-L. Ma, C.-H. Leung, S.-C. Yan, N. Zhu, R. Abagyan and C.-M. Che, Chem. Eur. J., 2009, 15, 13008-13021.

145. Z.-Z. Wei, Q.-P. Qin, T. Meng, C.-X. Deng, H. Liang and Z.-F. Chen, Eur. J. Med. Chem., 2018, 145, 360-369.

146. Q.-P. Qin, T. Meng, M.-X. Tan, Y.-C. Liu, S.-L. Wang, B.-Q. Zou and H. Liang, MedChemComm, 2018, 9, 525-533. 